\title{
Association of Social-cognitive Factors With Individual Preventive Behaviors of Covid-19 Among a Mixed-sample of Older Adults From China and Germany
}

\author{
Duan Yanping \\ Hong Kong Baptist University \\ Lippke Sonia ( $\nabla$ s.lippke@jacobs-university.de ) \\ Jacobs University Bremen \\ Liang Wei \\ Hong Kong Baptist University \\ Borui Shang \\ Hebei Sport University \\ Wagner Petra \\ Leipzig University \\ Julien Steven Baker \\ Hong Kong Baptist University \\ He Jiali \\ Wuhan Institute of Physical Education \\ Franziska Marie Keller \\ Jacobs University Bremen
}

\section{Research Article}

Keywords: COVID-19 pandemic, individual preventive behaviors, motivational and volitional factors, older adults, mixed sample

Posted Date: May 10th, 2021

DOI: https://doi.org/10.21203/rs.3.rs-503762/v1

License: (c) (i) This work is licensed under a Creative Commons Attribution 4.0 International License. Read Full License 


\section{Abstract}

Background: Older adults are vulnerable to infection and infections developing into severe diseases during the COVID-19 pandemic. Performing individual preventive behaviors including hand washing frequently, facemask wearing and physical distancing play an important role to reduce the transmission of COVID-19 in the community. Identifying key correlates of the preventive behaviors that are modifiable through intervention is a recognized priority. This study aimed to examine the association of social-cognitive factors (motivational and volitional factors) with preventive behaviors in a mixed-sample of older adults from China and Germany and to evaluate the moderating effects of countries on the associations of these factors with preventive behaviors.

Methods: Cross-sectional questionnaire surveys were conducted in China (June 2020 to July 2020) and Germany (June 2020 to February 2021). 578 older adults completed the online survey $\left(N_{\text {Chinese }}=356\right.$, mean age $=67.75, S D=6.24,39.6 \%$ females; $N_{\text {German }}=222$, mean age $=69.09, S D=6.9,63.5 \%$ females). The questionnaire consisted of demographics, three preventive behaviors (hand washing, facemask wearing and physical distancing) before and during the pandemic, motivational factors (health knowledge, attitude, subjective norm, risk perception, motivational self-efficacy, intention) and volitional factors (volitional self-efficacy, planning and self-monitoring) of preventive behaviors. Univariate linear regressions and multiple hierarchical linear regressions with simple slope analyses were used.

Results: The majority of motivational and volitional factors were associated with three preventive behaviors with small-tomoderate effect sizes $\left(f^{2}=.02\right.$ to .17$)$, when controlling for demographics and past preventive behaviors. When country was included in the regression models, it predicted all three preventive behaviors. Country also moderated five associations, including 1) volitional self-efficacy and hand washing, 2) self-monitoring and facemask wearing, 3) motivational selfefficacy and physical distancing, 4) volitional self-efficacy and physical distancing, and 5) planning and physical distancing.

Conclusions: Findings underline the generic importance of modifiable factors and addressing them through preventive behavior interventions especially increasing health knowledge, developing intentions and plans, and strengthening selfefficacy among older adults. Country-related mechanisms should be considered when aiming to learn from other countries on the promotion of preventive behaviors.

\section{Background}

The novel coronavirus disease 2019 (COVID-19) pandemic has been the most severe global public health crisis since January 2020, which has caused over 144 million confirmed cases and more than 3 million deaths worldwide inclusive of 23 April 2021 [1]. As a vulnerable population group, older adults suffered the most, accounting for nearly $75 \%$ of the COVID-19 relevant mortality globally [2,3]. As older people are especially vulnerable to developing a severe disease, they need special attention not only to be shielded but also in terms of identifying ways to protect themselves.

Given that there has been very limited effective vaccination prevention for COVID-19 worldwide, performing individual preventive behaviors including hand washing frequently, facemask wearing and physical distancing from social individuals in public areas play a very important role to reduce the transmission of COVID-19 in the community [4-6]. Public health organizations have been striving to develop behavioral interventions to promote individual preventive behaviors among the general population. Identifying key correlates of the preventive behaviors that are potentially modifiable through intervention, that can be targeted in messages or campaigns of behavioral intervention aimed at promoting preventive behaviors, is a recognized priority [7].

Recently there have been many studies investigating preventive behaviors and their social-cognitive factors in the general population during the COVID-19 pandemic [8-10]. However, most of these studies targeted only one or two preventive behaviors and very few addressed all three behaviors. This is even less among older adults. 
To maximize the prediction of social-cognitive factors towards behavior change, a comprehensive review of these factors is needed. In general, social-cognitive factors of behavior change comprise motivational factors associated with behavior initiation and volitional factors associated with behavior maintenance. The Theory of Planned Behavior (TPB) identified specific motivational factors, including attitude (positive or negative evaluations towards the consequences of performing the intended behavior), subjective norm (perceived expectations of important others approving the intended behavior), perceived behavioral control (perception about being able to perform the intended behavior) and intention [11]. These factors of TPB have shown significant predictions related to hand washing [12,13] and facemask wearing [14]. In addition, previous research has also shown that health knowledge, as an important factor influencing the formation of behavior intention, was significantly associated with hand washing behavior among adults $[15,16]$. Recent research has indicated that residents' COVID-19 knowledge was significantly associated with their preventive behaviors including facemask wearing and keeping physical distance [17].

The Health Action Process Approach (HAPA) suggests attention to critical psychological factors both in the motivational phase and volitional phase [18]. During the motivational phase, risk perception (perceived susceptibility to a health threat in terms of both perceived vulnerability and perceived severity) and motivational self-efficacy (the beliefs about the ability to start the behavior even when facing difficulty) are considered important to form the intention of preventive behaviors (e.g., facemask wearing) [19]. After the intention is formed, self-regulatory strategies (e.g., planning, volitional self-efficacy and self-monitoring) need to be enacted to ensure an intention is realized, and once initiated, maintained in the volitional phase. In particular, planning includes action planning about "when", "where," and "how" to act as well as coping planning about how to overcome anticipated barriers to the action. Volitional self-efficacy contains beliefs about the capabilities to overcome barriers during the maintenance period and to regain control after a setback. Finally, self-monitoring adjusts behavior by monitoring when, where, and how long to perform the behavior. The prediction function of planning, volitional self-efficacy and self-monitoring is supported in hand washing and facemask wearing research $[19,20]$.

As perceived behavior control (PBC) in TPB shares a synonymous construct with motivational self-efficacy in HAPA [21], this study used motivational self-efficacy instead of PBC. After a review of the main social-cognitive factors (motivation and volition factors) of behaviors, this study adopted the motivational factors including attitude, subjective norm, motivational self-efficacy, risk perception, health knowledge and intention, as well as the volitional factors including planning, volitional self-efficacy and action control. It is significant to adopt both motivational and volitional factors of preventive behaviors of COVID-19 in this study as most of the recent studies only focus on the motivational phase of preventive behaviors $[12,17,22]$.

In addition, it has been known that some preventive measures such as hand washing and facemask wearing diverge across Eastern and Western hemispheres [23,24,25]. The impact of cross-cultural/country differences (e.g., China vs. Germany) on the association between preventive behaviors and their social-cognitive factors in the context of the current pandemic has not been well explored until now.

To fill the evidence gap, this study aimed to investigate (1) the association of selected motivational factors and volitional factors with three preventive behaviors of older adults from China and Germany during the COVID-19 pandemic; (2) the moderating effect of culture/ country (China vs. Germany) on the associations of these factors with three preventive behaviors.

\section{Methods}

Study design, participants and procedure

This study adopted a cross-sectional design using an online questionnaire survey. To be eligible for inclusion, participants needed to meet the eligibility criteria: 1) aged 55 years or older; 2) have not been infected with the COVID-19; 3) have access to a mobile phone or laptop with internet connection; and 4) are able to read Chinese (for Chinese samples) or German (for German sample). 
In China, participants were recruited using a convenient sampling approach from Wuhan, Hubei Province of China, which was the most seriously infected region during the COVID-19 pandemic in China in 2020. Data collection started on June 15, 2020 and was completed on July 10, 2020 (the lockdown had been withdrawn for around two months). We invited 434 older adults to attend the survey and 356 participants (Mean age $=67.75, \mathrm{SD}=6.24$, age range: $58-89$ ) completed the online survey ( $82 \%$ response rate). The survey was constructed and administered using an online survey platform in China, namely SOJUMP (Changsha Ranxing Information Technology Co., Ltd., China). All recruitment posters and the hyperlink for the survey were disseminated via a mobile Short Message Service (SMS) and popular social media platforms in China (e.g., WeChat, Weibo, and QQ). Three approaches were used for recruiting participants: 1) Relying on the researchers' personal social networks in Wuhan, the eligible family members, friends and relatives of the researchers were invited. The participants then encouraged their friends to attend the survey; 2) Researchers contacted the directors of community neighborhood committees in Wuhan, respectively and sought their collaboration and support. Upon receiving the agreement of directors, researchers were permitted to enter into their community neighborhood WeChat groups to recruit eligible participants; 3 ) Researchers contacted officials who were in charge of the retirement in two universities in Wuhan. With the support of officials, a recruitment poster and survey hyperlink were delivered to their internal WeChat group, especially for retirement colleagues.

In Germany, participants were recruited through snowball sampling (personal contacts), press releases, social media groups (such as Facebook groups) and newspaper articles. Data collection was not limited to a city or a state. Rather a national wide recruitment was performed. The survey was set up and administered via the online survey tool Unipark. All data was collected anonymously. Data collection started on June 16, 2020 and was completed on February 17, 2021. 264 participants attended the survey. After excluding participants aged below 55 years, 222 eligible participants (Mean age $=69.09, S D=6.9$, age range: 55-86) were involved in the study.

All participants in China and Germany were asked to sign an informed consent form on the first page of the survey platform before completing the questionnaires. Ethical approval for the study in China was obtained from the Research Ethics Committee of Hong Kong Baptist University (REC/19-20/0490). For the German study, ethical approval was obtained from the Ethics Committee of Jacobs University (Application Number: 2020_09).

The sample in China was different from the sample in Germany concerning the majority of demographic variables, including age $\left(t_{576}=-2.41, p<.05\right)$, Body Mass Index (BMI) $\left(t_{576}=-7.72, p<.001\right)$, gender (females ${ }_{\text {China }}=39.6 \%$, females Germany $=$ $63.5 \% ; \chi_{1}^{2}=31.28, p<.001$ ), marital status (single ${ }_{\text {china }}=16.9 \%$, single Germany $=86.9 \% ; \chi_{1}^{2}=275.07, p<.001$ ), education level (secondary school and above ${ }_{\text {china }}=93.7 \%$, secondary school and above Germany $=84.3 \% ; \chi_{1}^{2}=21.8, p<.001$ ), occupation status (unemployed $_{\text {china }}=98.6 \%$, unemployed Germany $=76.9 \% ; \chi_{1}^{2}=72.79, p<.001$ ), household income (average and above $_{\text {china }}=79.8 \%$, average and above Germany $=89.7 \% ; \chi_{1}^{2}=70.78, p<.001$ ), living situation (living with children $/$ spouse $_{\text {china }}=91 \%$, living with children/spouse Germany $\left.\left.=68.5 \% ; \chi^{2}{ }_{1}\right)=47.81, p<.001\right)$, chronic disease (yes china $=$ $53.1 \%$, yes Germany $=42.8 \% ; \chi_{1}^{2}=5.57, p<.05$ ), infected acquaintances (yes ${ }_{\text {china }}=12.6 \%$, yes Germany $=37.4 \% ; \chi^{2}{ }_{1}=51.96, p$ $<.001$ ), and perceived health status (satisfactory and above ${ }_{\text {china }}=91.6 \%$, satisfactory and above Germany $=85.5 \% ; \chi^{2}{ }_{1}=$ $29.92, p<.001)$. See Table 1.

\section{Measurement}

A series of questionnaires were used to investigate older adults' demographic information, preventive behaviors, motivational and volitional factors of preventive behaviors. All questionnaires were adapted from well-established ones in previous studies and back-translated to Chinese and German by 2 independent bilingual translators. Each participant took 15-20 minutes to complete all online questionnaires. The questionnaire items and reliability are presented as follows: 
The demographic characteristics included age, gender, marital status, country, living situation, education level, occupational status, household income, children status. Participants were also invited to report their chronic disease situation, infected acquaintances, perceived health status, height $(\mathrm{cm})$ and weight $(\mathrm{kg})$.

\section{Preventive Behaviors}

Preventive behaviors during the COVID-19 pandemic

Hand washing behavior was measured using two items in accordance with the World Health Organization's (WHO) recommendations. The frequency of hand washing behavior was evaluated with the stem "During the previous week, how frequently did you wash your hands with soap and water or alcohol-based hand rub (for at least 20 seconds, all surfaces of the hands)... ", followed by two kinds of situations, i.e., "in the daily life situations (e.g., before preparing food; before eating; after defecation)" or "in disease-related situations (e.g., after blowing nose or sneezing; before and after caring for the sick)". Older adults were asked to rate the two items on a 4-point Likert scale ranging from (1) never to (4) always. A higher total score indicated better hand washing behavior.

Facemask wearing behavior was measured with two items in accordance with the WHO recommendations. The questions were asked using the stem "During the previous week, I have usually worn a facemask properly..." followed by two different situations relevant to older adults, i.e., "when visiting public places (e.g., public transportation, supermarket)", and "caring for a person with suspected COVID-19 infection". Responses were scored on a 4-point Likert scale ranging from (1) strongly disagree to (4) strongly agree.

Physical distancing behavior was measured with two items according to the WHO recommendations. Participants were asked to assess their physical distancing behavior during the past week, with items such as "a) usually stayed out of crowded places or mass gatherings, and b) usually kept space (at least 1.5 meters) between myself and other people who are coughing or sneezing." Answers were given on a 4-point Likert scale from (1) strongly disagree to (4) strongly agree.

Past preventive behaviors before the COVID-19 pandemic

Participants were asked to recall their three preventive behaviors before the pandemic of COVID-19 respectively. Items of each past preventive behavior were identical to those during the COVID-19 pandemic aforementioned.

\section{Motivational Factors of Preventive Behaviors}

Risk perception was measured using one item for three preventive behaviors respectively, which was adapted from previous studies $[26,27]$. The participants were asked" Compared to an average person of your age and gender, what is your risk of COVID-19 infection from lack of frequent hand washing/facemask wearing/physical distancing?" with responses rated on a 6-point Likert scale from $1=$ very low to $6=$ very high.

Health knowledge was measured using one item for three preventive behaviors respectively, which was adapted from previous studies $[28,29]$. The participants were asked "Have you known how and in what situations to wash hands/ wear a facemask/ keep a safe physical distancing in accordance with the WHO recommendations?" with responses rated on a 4point scale with 1 (do not know), 2 (a little), 3 (most) and 4 (all). The higher score represented more sufficient health knowledge.

Attitude was assessed using a common stem on three preventive behaviors. Such as "For me to wash hands frequently/wear a facemask/keep a safe physical distance during the outbreak of COVID-19 would be..." followed by two semantic differential items. Items were rated on a 6-point Likert scale: troubling-reassuring (1-6) and optional-necessary (1-6) [30,31]. A high total score means a positive attitude. The Cronbach alpha coefficient was .69 (China) and .75 (Germany) for hand washing behavior, .74 (China) and .77 (Germany) for mask wearing behavior and .80 (China) and .65 (Germany) for physical distancing behavior. 
Subjective norm was assessed using one item measuring participants' perceptions of important others' approval on the three preventive behaviors [14,32]. The participants were asked "Most people who are important to me (e.g., my family members, friends, doctors) think that I should wear a facemask during the outbreak of COVID-19." with responses rated on a 6-point Likert scale, from 1 = strongly disagree to 6 = strongly agree.

Intention was assessed with one item for three preventive behaviors respectively, which was adapted from previous studies $[33,34]$. The participants were asked "Today and in the near future, I intend to frequently wash my hands in various situations (e.g., before eating, after going to the washroom, after blowing my nose or sneezing)" for hand washing, "Today and in the near future, I intend to properly wear a facemask in various situations (e.g., visiting public places)" for mask wearing behavior, and "Today and in the near future, I intend to keep a safe physical distance in various situations (e.g., staying out of crowded places or mass gatherings when I go outside of my home)" for physical distancing. Items were rated on a 6 -point Likert scale, from $1=$ strongly disagree to $6=$ strongly agree.

Motivational self-efficacy was assessed using one item measuring older adults' level of confidence in starting to act on preventive behaviors. The participants were asked "I feel certain that I can begin to wash my hands frequently/ wear a facemask/ keep a safe physical distance, even if it would be difficult to change my routines." with responses rated on a 6point Likert scale, from $1=$ totally disagree to $6=$ totally agree $[19,33]$.

\section{Volitional Factors of Preventive Behaviors}

Volitional self-efficacy was assessed using one item measuring participants' confidence of recovery of the behaviors, respectively. The participants were asked "I feel certain that I can restart to wash my hands frequently/wear face mask/keep a secure physical distance even if I forgot to do it a few times" with responses rated on a 6-point Likert scale, from $1=$ totally disagree to 6 = totally agree [19.33].

Planning included action planning and coping planning. Action planning was assessed with one item for three preventive behaviors respectively. The items were "I have already made a concrete action plan for hand washing regarding when, where and how to..." followed by "wash my hands/wear face mask/keep a safe physical distance". Coping planning was assessed by the item "I have made a coping plan to maintain frequent hand washing/mask wearing/physical distancing if I am confronted with some barriers". Answers were given on a 6-point Likert scale from $1=$ totally disagree to $6=$ totally agree $[6,13,33,35]$. The Cronbach's alpha coefficient was .75 (China) and .80 (Germany) for hand washing behavior, .84 (China) and .82 (Germany) for mask wearing behavior and .74 (China) and .83 (Germany) for physical distancing behavior.

Self-monitoring was assessed using one item measuring participants' perceptions of their self-regulation over the preventive behaviors. The participants were asked "I have consistently monitored myself about how and in what situations to wash my hands/wear a face mask/keep a safe physical distance", with responses rated on a 6-point Likert scale, from $1=$ strongly disagree to 6 = strongly agree $[13,35]$.

\section{Statistical Analysis}

Data analysis was conducted using IBM SPSS 26.0 (Armonk, NY, USA). Descriptive analyses including percentages used to present demographic differences between Chinese and German older adults and were examined with an independent $t$-test and Chi-squared test. Moreover, the association of demographics and past preventive behaviors with the current three preventive behaviors were examined by t-tests, F-tests and Pearson/Spearman correlations. In addition, a series of univariate linear regressions were used to analyze the associations of social-cognitive factors with three preventive behaviors after control demographics and past behaviors. Furthermore, the moderating effect of the country on the association between social-cognitive factors and preventive behaviors was examined using multiple hierarchical linear regressions, where all independent variables were standardized using Z scores to avoid the collinearity problem. To further elaborate the magnitude of the association between preventive behaviors and their associated factors in regression analyses, effect size $(t$ 
${ }^{2}$ ) was estimated with the conversion formula: $f^{2}=R^{2} /\left(1-R^{2}\right)$, with $.02, .15$, and .35 indicating a small, medium and large effect, respectively.

\section{Results}

\section{Descriptive information of three preventive behaviors, motivational factors and volitional factors of three preventive behaviors}

As outlined in Table 2, for hand washing behavior (Mean $=3.35, \mathrm{SD}=0.6)$, there were significant differences in country $(t$ adjust $=10.78, p<.001)$, marital status $\left(t_{\text {adjust }}=-7.88, p<.001\right)$, occupation status $(t=3.89, p<.001)$, household income $(F=$ $3.09, p=.016)$, children status $(t=4.66, p<.001)$, living situation $\left(t_{\text {adjust }}=-2.73, p=.007\right)$, and infected acquaintances $(t=$ $-3.79, p<.001)$. Hand washing was also significantly associated with age $(r=-.09, p=.025), \mathrm{BMI}(r=-.19, p<.001)$, and past behavior $(r=.49, p<.001)$. For facemask wearing behavior (Mean $=3.76, \mathrm{SD}=0.51)$ and physical distancing behavior (Mean $=3.64, \mathrm{SD}=0.48$ ), no significant differences were found in demographic variables (all $p>.05$ ). Both behaviors were significantly correlated to the past behavior $\left(r_{\text {facemask wearing }}=.09, p=.024 ; r_{\text {physical distancing }}=.29, p<.001\right)$. The descriptive information of motivational factors and volitional factors for each preventive behavior (mean value, SD) is also presented in Table 2.

\section{Association of motivational factors, volitional factors with three preventive behaviors}

When controlling for significant demographics and past preventive behaviors, the associations of motivational factors and volitional factors with preventive behaviors in the univariate regression analysis are presented in Table 3. Hand washing was significantly correlated to all motivational and volitional factors with small effect sizes $\left(f^{2}=.02\right.$ to .08$)$, except for the risk perception $(\beta=.05,95 \% \mathrm{Cl}=-.01-.05, p=.24)$. Facemask wearing was significantly correlated to all motivational and volitional factors with small effect sizes $\left(f^{2}=.01\right.$ to .14$)$, except for the health knowledge $(\beta=.06,95 \% \mathrm{Cl}=-.01-.07, p=.17)$. Physical distancing was significantly associated with all motivational and volitional factors with small-to-moderate effect sizes $\left(f^{2}=.01\right.$ to .17$)$.

\section{Country moderating the associations of social-cognitive factors with three preventive behaviors}

\section{Hand washing behavior}

Except country, significant demographic variables and past behaviors were first entered as independent variables in Model 1 (See Table 4). The linear combination of all aforementioned variables significantly predicted hand washing behavior $\left(R^{2}=\right.$ $\left..33, F_{(9,559)}=29.64, p<.001\right)$. The significant motivational factors and volitional factors revealed in univariate analyses were entered in Model 2 and Model 3, respectively. In Model 2, only health knowledge, attitude and intention significantly contributed to the model $\left(R^{2}\right.$ change $\left.=.11, F_{(14,559)}=29.57, p<.001\right)$, while in Model 3 only the planning significantly contributed to the model $\left(R^{2}\right.$ change $\left.=.02, F_{(17,559)}=26.53, p<.001\right)$. Country was entered in Model 4 and significantly contributed to this model $\left(R^{2}\right.$ change $\left.=.01, F_{(18,559)}=26.31, p<.001\right)$. Finally, the interactions between country and these social-cognitive factors were entered in Model 5 . Terms for the interaction between country and volitional self-efficacy significantly contributed to the model $\left(R^{2}\right.$ change $\left.=.02, F_{(26,559)}=19.20, p<.001\right)$. The full model (Model 5) eventually accounted for $48 \%$ of variance in hand washing behavior. In addition, the effect size $\left(f^{2}\right)$ of association for each model showed that Model $1 f^{2}=0.49$, Model $2 f^{2}=0.76$, Model $3 f^{2}=0.83$, Model $4 f^{2}=0.88$, and Model $5 f^{2}=0.94$, suggesting the large effect of association $\left(f^{2}>0.35\right)$ was in all these models.

To further explore the interaction term, a simple slope analysis was employed to examine the moderating effect of the country on the associations of volitional self-efficacy with hand washing. As shown in Figure 1, there was no significant 
relationship between volitional self-efficacy and hand washing behavior in Germany $(\beta=-.02,95 \% \mathrm{Cl}=[-.09, .05], p=.54)$, whereas a significant positive correlation was found in China $(\beta=.14,95 \% \mathrm{Cl}=[.05, .23], p=.002)$.

\section{Facemask wearing behavior}

As all demographic variables were not significantly correlated to facemask wearing behavior in the aforementioned test, only past behavior as a covariance was added to Model 1 (see Table 5), where the linear model significantly predicted facemask wearing behavior $\left(R^{2}=.01, F_{(1,577)}=5.12, p=.024\right)$. The significant motivational factors and volitional factors identified in univariate analyses were entered in Model 2 and Model 3, respectively. In Model 2, only motivational self-efficacy significantly contributed to the model $\left(R^{2}\right.$ change $\left.=.12, F_{(6,577)}=14.30, p<.001\right)$, while in Model 3 only volitional selfefficacy significantly contributed to this model $\left(R^{2}\right.$ change $\left.=.04, F_{(9,577)}=12.68, p<.001\right)$. Country was entered in Model 4 and significantly contributed to this model $\left(R^{2}\right.$ change $\left.=.05, F_{(10,577)}=15.40, p<.001\right)$. Finally, the interactions between country and these social-cognitive factors were entered in Model 5 . Terms for the interaction between country and selfmonitoring significantly contributed to this model $\left(R^{2}\right.$ change $\left.=.03, F_{(18,577)}=9.78, p<.001\right)$. The full model (Model 5) eventually accounted for $24 \%$ of variance in facemask wearing behavior. The effect size $\left(f^{2}\right)$ of factors associations for each model increased from a small level to a moderate level, with Model $1 f^{2}=0.01$, Model $2 f^{2}=0.15$, Model $3 f^{2}=0.20$, Model 4 $f^{2}=0.27$, and Model $5 f^{2}=0.31$.

Figure 2 presents the result of simple slope analysis. Results showed that there was a significant positive association between self-monitoring and facemask wearing behavior in China $(\beta=.22,95 \% \mathrm{Cl}=[.09, .35], p<.001)$, whereas the association was not significant in Germany $(\beta=-.03,95 \% \mathrm{Cl}=[-.12, .06], p=.53)$.

\section{Physical distancing behavior}

As all demographic variables were not significantly correlated to physical distancing behavior in the aforementioned test, only past behavior as a covariance was added to Model 1 (see Table 6), where the linear model significantly predicted physical distancing behavior $\left(R^{2}=.08, F_{(1,577)}=53.02, p<.001\right)$. In Model 2 where the motivational factors were added, only intention significantly contributed to this model $\left(R^{2}\right.$ change $\left.=.13, F_{(7,577)}=21.20, p<.001\right)$. In Model 3 , only volitional selfefficacy significantly contributed to the model $\left(R^{2}\right.$ change $\left.=.03, F_{(10,577)}=18.70, p<.001\right)$. Country was entered in Model 4 and significantly contributed to this model $\left(R^{2}\right.$ change $\left.=.08, F_{(11,577)}=24.80, p<.001\right)$. Finally, for the interaction terms, country $\mathrm{x}$ motivational self-efficacy, country $\mathrm{x}$ volitional self-efficacy, and country $\mathrm{x}$ planning significantly contributed to the Model $5\left(R^{2}\right.$ change $\left.=.02, F_{(20,577)}=14.77, p<.001\right)$. The full model (Model 5$)$ accounted for $35 \%$ of variance in physical distancing behavior. Results indicated a small effect size of factor associations for Model $1\left(f^{2}=0.09\right)$, a moderate effect size for Model 2 and $3\left(f^{2}=0.27\right.$ and 0.33$)$, and a large effect size for Model 4 and $5\left(f^{2}=0.48\right.$ and 0.53$)$.

Figure 3-5 present the results of simple slope analyses. It was revealed that the association between motivational selfefficacy and physical distancing was not significant in Germany $(\beta=-.03,95 \% \mathrm{Cl}=[-.11, .05], p=.51)$, whereas a significant positive association was found in China $(\beta=.10,95 \% \mathrm{Cl}=[.01, .19], p=.03)$ (see Figure 3 ). For volitional self-efficacy, it was found to be significantly and positively correlated to physical distancing behavior in Germany $(\beta=.14,95 \% \mathrm{Cl}=[.06, .23], p<$ $.001)$, whereas the association was not significant in China $(\beta=.01,95 \% \mathrm{Cl}=[-.08, .09], p=.84)$ (see Figure 4). For planning, a significant positive association with physical distancing was found in China $(\beta=.17,95 \% \mathrm{Cl}=[.06, .29], p=.004)$, but was not found in Germany $(\beta=.02,95 \% \mathrm{Cl}=[-.05, .09], p=.56)$ (see Figure 5).

\section{Discussion}

This study was conducted to examine the association of social-cognitive factors with preventive behaviors of older adults and to evaluate the moderating effect of culture/country on the associations of factors with preventive behaviors of the 
elderly.

Findings of the current study revealed differences in three preventive behaviors namely hand washing, facemask wearing and physical distancing in public areas in older adults between China and Germany. This was noted even after controlling for demographic, motivational and volitional factors: While older adults in China performed more hand washing behavior, older adults in Germany performed more facemask wearing behavior and physical distancing in public spaces.

Without controlling for demographics, all recorded motivational and volitional factors were significantly associated with the three behaviors: As motivational factors, health knowledge, attitude, subjective norm, risk perception, motivational selfefficacy and intention were imperative for performing the behaviors. In addition, the volitional factors such as volitional selfefficacy, planning and self-monitoring also revealed importance in predicting preventive behaviors in the mixed sample. These results are in line with previous findings [12-17]. As a result of these findings, previously identified key correlates of the preventive behaviors are suitable targets for intervention, that is, they can be addressed with messages or campaigns of behavioral intervention aimed at promoting preventive behaviors [7]. When taking demographic factors such as marital status and BMI, into account to predict hand washing behavior, past behavior, health knowledge, intention and planning remained significantly associated. Interestingly, when also taking the country into account, demographic factors were not significantly interrelated with the behavioral outcome variables anymore. This underlines that differences between the two countries cannot be attributed to demographic factors but rather to cultural differences. Empirical support was found that an interaction of country and volitional self-efficacy exists underlining the moderating effect of culture/country (China vs. Germany) on the associations of these factors for hand washing behavior and that attitude as well as volitional self-efficacy could explain additional variance. In brief, when designing hand washing behavioral interventions in China and Germany, past behavior, health knowledge, attitude, volitional self-efficacy and planning should be addressed and in China even further attention should be put on increasing volitional self-efficacy.

When investigating facemask wearing, only two motivational factors revealed imperative namely past behavior and motivational self-efficacy, but volitional self-efficacy was not significantly interrelated when country was included in the model. When investigating the potential moderating role of the country it turned out that there was only interaction with selfmonitoring: While self-monitoring could not be further increased with more self-monitoring in Germany, in China selfmonitoring was related to more facemask wearing behavior.

Regarding physical distancing, past behavior, health knowledge and volitional self-efficacy remained significant also when taking the country into account. Country was not only a moderator for motivational self-efficacy but also for volitional selfefficacy and planning. Importantly, past behavior, health knowledge, intention and planning also remained with their main effects on behavior independently of country underlining their generic importance: Only if individuals know why and how to perform physical distancing, and if they have performed this before and intend to repeat it, then they are more likely to also adopt and maintain this behavior. In contrast, self-efficacy needs to be addressed country-specific: while in China, more motivational self-efficacy is imperative for more preventive physical distancing, in Germany more volitional self-efficacy seems to be required.

The findings of this study fill the evidence gap because no such comparative study was published prior to testing these motivational and volitional factors for all three preventive behaviors of older adults. Concluding regarding the research questions, this study presents unique findings: (1) the association of selected motivational factors and volitional factors with three preventive behaviors of older adults from China and Germany during the COVID-19 pandemic is not only generic for some factors but also specific for others. (2) The moderating effect of culture/country (China vs. Germany) on the associations of these factors with three preventive behaviors revealed importance especially for motivational self-efficacy (China-physical distancing), volitional self-efficacy (China-hand washing and Germany-physical distancing) as well as selfmonitoring (China-facemask wearing). This should be considered when aiming to learn from other countries: aiming to improve physical distancing in Germany in the same way as in China may not work as different self-efficacy beliefs need to be addressed (motivational in China and volitional in Germany). Remarkably, risk perception was not imperative although

Page 9/27 
most campaigns aim to make individuals more aware of the risks. In contrast, health knowledge and the other motivational and volitional factors are more important underlining the importance of mastery (past behavior) and communicating own controllability in terms of intention, planning and self-efficacy.

As there is still not enough vaccination prevention for COVID-19 worldwide and in anticipation of rapidly mutating viruses which transitions may not be prevented by vaccinations, performing individual preventive behaviors including frequent hand washing, facemask wearing and physical distancing in public areas plays a very important role to reduce the transmission of COVID-19 and other communicable diseases in the community [4,5]. Public health organizations striving to develop behavioral interventions to promote individual preventive behaviors among the general population should accordingly take the findings of this study into account. While this study only investigated older adults, further research should investigate the association of social-cognitive factors with individual preventive behaviors of COVID-19 between different cultural samples among different age groups. Furthermore, while we revealed differences between the two countries, more research needs to be done also on intercultural differences within countries relating to the background of the individuals residing there. So far, we can only assume that individuals living in China are different from individuals living in Germany and the identified key correlates of the preventive behaviors should be modified through intervention. Evidence-based targeting can be informed accordingly. However, whether further tailoring on a more individual basis is even more effective by messages or campaigns with behavioral interventions regarding promoting preventive behaviors [7] still needs to be further investigated as this study was only correlational. Hence, the cross-sectional design of this study limits the ability to infer causal relationships and data collection at multiple time points during the COVID-19 pandemic may yield different results due to the nature of the study's design. Accordingly, future studies should apply longitudinal designs with ideally also experimental tests of effectiveness for more effective messages or campaigns in different countries and with individuals with different cultural backgrounds.

\section{Conclusion}

In conclusion, the findings of the current study support the design of more effective messages or campaigns: Not only does health knowledge need to be addressed but importantly the factors more closely correlated with behavior change such as intention, planning and self-efficacy. While country-related mechanisms seem to exist, findings underline the generic importance of modifiable factors and addressing them through intervention especially in a resource-oriented way communicating the need and controllability of the behaviors. As older people are especially vulnerable to develop a severe disease, protecting themselves is key in the long term. We should also help this population to develop intentions and plans and strengthen their self-efficacy.

\section{Abbreviations}

COVID-19: Coronavirus disease 2019

TPB: Theory of Planned Behavior

HAPA: Health Action Process Approach

PBC: Perceived behavior control

WHO: World Health Organization

BMI: Body Mass Index

SD: Standard deviation

Cl: Confidence interval 


\section{Declarations}

\section{Acknowledgements}

We acknowledge support from the Konfuzius Institute Bremen/Hanban.

\section{Authors' Contributions}

YD, SL, WL, BS and CH conceived and designed the study. YD, WL, BS, JH, CH and YW contributed to the preparation of study materials and data collection in China. SL, FK and PW contributed to the preparation of study materials and data collection in Germany. WL, YD, JH and BS screened and analyzed the mixed-sample data. YD, SL, WL, BS and FK drafted and revised the manuscript. JSB, YD and SL polished the manuscript. All authors read and approve the final manuscript.

\section{Funding}

This research was supported by the Start-up Grant of Hong Kong Baptist University. The Open Access Fee was provided by the Konfuzius Institute Bremen/Hanban. The funding organization had no role in the study design, study implementation, data collection, data analysis, manuscript preparation, or publication decision. The work is the responsibility of the authors.

\section{Availability of data and materials}

Requests of data and materials should be directed to the study directors: Dr. Duan Yanping (duanyp@hkbu.edu.hk) and/or Prof. Sonia Lippke (s.lippke@jacobs-university.de).

\section{Ethics approval and consent to participate}

The Chinese study received ethical approval by the Research Ethics Committee (REC) at the Hong Kong Baptist University (Ref: REC/19-20/0490). For the German study, ethical approval was obtained from the Ethics Committee of Jacobs University (Application Number: 2020_09). The study was undertaken in accordance with the Declaration of Helsinki. We confirmed that all participants were informed about the purpose of the study with a written informed consent form on the first page of online questionnaire survey.

\section{Consent for publication}

Data are only reported in aggregate and cannot be attributed to individuals.

\section{Competing interests}

The authors declare that they have no competing interests.

\section{References}

1. Center for Systems Science and Engineering (CSSE). Johns Hopkins University, USA. 23 April 2021. Derived from https://gisanddata.maps.arcgis.com/apps/opsdashboard/index.html\#/bda7594740fd40299423467b48e9ecf6.

2. Kluge HHP. Statement - Older people are at highest risk from COVID-19, but all must act to prevent community spread. 2 April 2020, Copenhagen, Denmark, Dr Hans Henri P. Kluge, WHO Regional Director for Europe. Derived from http://www.euro.who.int/en/health-topics/health-emergencies/coronavirus-covid-19/statements/statement-olderpeople-are-at-highest-risk-from-covid-19,-but-all-must-act-to-prevent-community-spread.

3. Shahid Z, Kalayanamitra R, McClafferty B, et al. COVID-19 and older adults: what we know[J]. Journal of the American Geriatrics Society, 2020, 68(5): 926-929.PMID: 32255507.

4. Broomell S B, Chapman G B, Downs J S. Psychological predictors of prevention behaviors during the COVID-19 pandemic[J]. Behavioral Science Policy, 2020: 1-8. Retrieved from https://behavioralpolicy.org/journal_issue/covid-19/ 
5. Doung-ngern P, Suphanchaimat R, Panjangampatthana A, et al. Associations between wearing masks, washing hands, and social distancing practices, and risk of COVID-19 infection in public: a cohort-based case-control study in Thailand[J]. 2020.

6. Liang W, Duan Y, Shang B, Hu C, Baker JS, Lin Z, He J, Wang Y. Precautionary behavior and depression in older adults during the COVID-19 pandemic: an online cross-sectional study in Hubei, China. International journal of environmental research and public health. 2021 Jan;18(4):1853.

7. Bonell C, Michie S, Reicher S, et al. Harnessing behavioural science in public health campaigns to maintain "social distancing" in response to the COVID-19 pandemic: Key principles. J Epidemiol Commun Health. 2020; 74:617-619. DOI: 10.1136/jech-2020-214290

8. Hagger M S, Smith S R, Keech J J, et al. Predicting social distancing intention and behavior during the COVID-19 pandemic: An integrated social cognition model[J]. Annals of Behavioral Medicine, 2020, 54(10): 713-727. doi: 10.1093/abm/kaaa073 PMID: 32914831.

9. Derksen C, Keller F M, Lippke S. Obstetric Healthcare Workers' Adherence to Hand Hygiene Recommendations during the COVID-19 Pandemic: Observations and Social-Cognitive Determinants[J]. Applied Psychology: Health and Well-Being, 2020, 12(4): 1286-1305. PMID: 33016518.

10. Raude J, Lecrique J M, Lasbeur $L$, et al. Determinants of preventive behaviors in response to the COVID-19 pandemic in France: comparing the sociocultural, psychosocial and social cognitive explanations[J]. Frontiers in Psychology, 2020, 11: 3345. doi: 10.3389/fpsyg.2020.584500 PMID: 33329241.

11. Ajzen I. From intentions to actions: A theory of planned behavior[M]//Action control. Springer, Berlin, Heidelberg, 1985: 11-39.

12. Gaube S, Fischer P, \& Lermer E. Hand(y) hygiene insights: Applying three theoretical models to investigate hospital patients' and visitors' hand hygiene behavior. BMC Public Health 2020. doi: 10.21203/rs.3.rs-21893/v1.

13. Zhang CQ, Fang, RY, Zhang, R, Hagger, MS, \& Hamilton, K. Predicting Hand Washing and Sleep Hygiene Behaviors among College Students: Test of an Integrated Social-Cognition Model. Int J Env Res Pub He 2020;17,1209.

14. Chung PK, Zhang CQ, Liu JD, Chan DKC, Si GY, Hagger MS. The process by which perceived autonomy support predicts motivation, intention, and behavior for seasonal influenza prevention in Hong Kong older adults. BMC Public Health 2018;18(1):65. doi:10.1186/s12889-017-4608-x.

15. Tao SY, Cheng YL, Lu Y, Hu YH, \& Chen DF. Handwashing behaviour among Chinese adults: A cross-sectional study in five provinces. Public Health 2013;127(7):620-628.

16. Ajilore K, Atakiti I, Onyenankeya K. College students' knowledge, attitudes and adherence to public service announcements on Ebola in Nigeria: Suggestions for improving future Ebola prevention education programmes[J]. Health Education Journal, 2017, 76(6): 648-660.

17. Zhong BL, Luo W, Li HM, Zhang QQ, Liu XG, Li WT, \& Li Y. Knowledge, attitudes, and practices towards COVID-19 among Chinese residents during the rapid rise period of the COVID-19 outbreak: A quick online cross-sectional survey. Int J Biol Sci 2020;16(10):1745-1752.

18. Schwarzer R. Modeling health behavior change: How to predict and modify the adoption and maintenance of health behaviors. Appl Psychol 2008;57(1):1-29. doi:10.1111/j.1464-0597.2007.00325.x.

19. Zhou G, Gan Y, Ke Q, Knoll N, Lonsdale C, \& Schwarzer R. Avoiding exposure to air pollution by using filtering facemask respirators: An application of the Health Action Process Approach. Health Psychol 2016;35(2):141-147.

20. Fernández BR, Knoll N, Hamilton K, \& Schwarzer R. Social-cognitive antecedents of hand washing: Action control bridges the planning-behaviour gap. Psychol \& Health 2016;31(8):993-1004.

21. Schwarzer R, \& Luszczynska A. Perceived self-efficacy. M. Conner, P. Norman. Predicting and changing health behaviour: Research and practice with social cognition models (3rd edition) 2005;225-251. 
22. Chen Y, Zhou R, Chen BY, Chen H, Li Y, Chen Z, Zhu HH,\& Wang HM. Knowledge, perceived beliefs, and preventive behaviors related to COVID-19 among Chinese older adults: Cross-sectional web-based survey. J Med Internet Res 2020;22(12):e23729.

23. Kumar S, Loughnan L, Luyendijk R, et al. Handwashing in 51 countries: analysis of proxy measures of handwashing behavior in multiple indicator cluster surveys and demographic and health surveys, 2010-2013[J]. The American journal of tropical medicine and hygiene, 2017, 97(2): 447-459.

24. Pogrebna G, Kharlamov A. The impact of cross-cultural differences in handwashing patterns on the COVID-19 outbreak magnitude[J]. Regulation and Governance. Advance Online Publication, 2020, 10. DOI: 10.13140/RG.2.2.23764.96649.

25. DeNardo, S. Face Masks show cultural differences. 3 March 2020. Report in the HAWK Newspaper. Derived from https://www.sjuhawknews.com/face-masks-show-cultural-differences/

26. Duan YP, Wienert J, Hu C, Si GY, Lippke S. Web-based intervention for physical activity and fruit and vegetable intake among Chinese university students: A randomized controlled trial. J Med Internet Res 2017;19(4):e106. doi:10.2196/jmir.7152.

27. Perloff LS, Fetzer BK. Self-other judgments and perceived vulnerability to victimization. J Pers Soc Psychol 1986;50(3):502-510. doi:10.1037//0022-3514.50.3.502

28. Li Y, Liu Y, Zeng L, Chen C, Mo D, Yuan S. Knowledge and practice of hand hygiene among hospitalised patients in a tertiary general hospital in China and their attitudes: A cross-sectional survey. BMJ Open 2019;9(6):e027736. doi:10.1136/bmjopen-2018-027736.

29. Contzen N, Mosler HJ. Identifying the psychological determinants of handwashing: Results from two cross-sectional questionnaire studies in Haiti and Ethiopia. Am J Infect Control 2015;43(8):826-832. doi:10.1016/j.ajic.2015.04.186.

30. O’Boyle CA, Henly SJ, Duckett LJ. Nurses' motivation to wash their hands: A standardized measurement approach. Appl Nurs Res 2001;14(3):136-145. doi:10.1053/apnr.2001.24412.

31. Rosen L, Zucker D, Brody D, Engelhard D, Manor O. The effect of a handwashing intervention on preschool educator beliefs, attitudes, knowledge and self-efficacy. Health Educ Res 2009;24(4):686-698. doi:10.1093/her/cyp004.

32. Ajzen I. Constructing a TPB questionnaire: Conceptual and methodological considerations[J]. 2002. doi:10.1080/09715010.2017.1408037.

33. Duan YP, Liang W, Guo L, Wienert J, Si GY, Lippke S. Evaluation of a web-based intervention for multiple health behavior changes in patients with coronary heart disease in home-based rehabilitation: Pilot randomized controlled trial. J Med Internet Res 2018;20(11):e12052. doi:10.2196/12052.

34. Lippke S, Ziegelmann JP, Schwarzer R, Velicer WF. Validity of stage assessment in the adoption and maintenance of physical activity and fruit and vegetable consumption. Heal Psychol 2009;28(2):183-193. doi:10.1037/a0012983.

35. Sniehotta FF, Scholz U, Schwarzer R. Bridging the intention-behaviour gap: Planning, self-efficacy, and action control in the adoption and maintenance of physical exercise. Psychol Heal 2005;20(2):143-160. doi:10.1080/08870440512331317670.

\section{Tables}

Table 1. Characteristics of overall sample and by country 


\begin{tabular}{|c|c|c|c|c|c|}
\hline & Overall & China & Germany & $x^{2} / t$ & $p$ \\
\hline Age, mean (SD) & $68.27(6.53)$ & $67.75(6.24)$ & $69.09(6.9)$ & -2.41 & .016 \\
\hline BMI, mean (SD) & $24.14(3.76)$ & $23.23(2.95)$ & $25.6(4.4)$ & -7.72 & $<.001$ \\
\hline Gender, n (\%) & & & & 31.28 & $<.001$ \\
\hline Female & $282(48.8 \%)$ & $141(39.6 \%)$ & $141(63.5 \%)$ & & \\
\hline Male & $296(51.2 \%)$ & $215(60.4 \%)$ & $81(36.5 \%)$ & & \\
\hline Marital status, n (\%) & & & & 275.07 & $<.001$ \\
\hline Single & $253(43.8 \%)$ & $60(16.9 \%)$ & 193(86.9\%) & & \\
\hline Married/partnered & $324(56.1 \%)$ & $296(83.1 \%)$ & $28(12.6 \%)$ & & \\
\hline Education level, n (\%) & & & & 21.8 & $<.001$ \\
\hline Primary school or below & $38(6.6 \%)$ & $20(5.6 \%)$ & $18(8.1 \%)$ & & \\
\hline Secondary school & $203(35.1 \%)$ & $154(43.2 \%)$ & $49(22.1 \%)$ & & \\
\hline University or above & $318(55 \%)$ & $180(50.5 \%)$ & $138(62.2 \%)$ & & \\
\hline Occupation status, n (\%) & & & & 72.79 & $<.001$ \\
\hline Employed/working & $54(9.3 \%)$ & $5(1.4 \%)$ & $49(23.1 \%)$ & & \\
\hline Unemployed & $514(88.9 \%)$ & $351(98.6 \%)$ & $163(76.9 \%)$ & & \\
\hline Household income, n (\%) & & & & 70.78 & $<.001$ \\
\hline Below the average & $94(16.3 \%)$ & $72(20.2 \%)$ & $22(10.3 \%)$ & & \\
\hline Average & $296(51.2 \%)$ & $217(61.0 \%)$ & 79(37.1\%) & & \\
\hline Above the average & $179(31.0 \%)$ & $67(18.8 \%)$ & $112(52.6 \%)$ & & \\
\hline Children status*, n (\%) & & & & NA & NA \\
\hline Yes (have children) & $521(90.1 \%)$ & $354(99.4 \%)$ & $167(75.2 \%)$ & & \\
\hline No & $57(9.9 \%)$ & $2(0.6 \%)$ & $57(25.7 \%)$ & & \\
\hline Living situation, n (\%) & & & & 47.81 & $<.001$ \\
\hline Living alone & $102(17.6 \%)$ & $32(9 \%)$ & $70(31.5 \%)$ & & \\
\hline Living with children/spouse & $476(82.4)$ & $324(91 \%)$ & $152(68.5 \%)$ & & \\
\hline Chronic disease, n (\%) & & & & 5.57 & .018 \\
\hline Yes & $284(49.1 \%)$ & 189(53.1\%) & $95(42.8 \%)$ & & \\
\hline No & $293(50.7 \%)$ & $167(46.9 \%)$ & $126(56.8 \%)$ & & \\
\hline Infected acquaintances, n (\%) & & & & 51.96 & $<.001$ \\
\hline Yes & $128(22.1 \%)$ & $45(12.6 \%)$ & $83(37.4 \%)$ & & \\
\hline No & $443(76.6 \%)$ & $311(87.4 \%)$ & $132(59.5 \%)$ & & \\
\hline Perceived health status, n (\%) & & & & 29.92 & $<.001$ \\
\hline Bad & $62(10.7 \%)$ & $30(8.4 \%)$ & $32(14.5 \%)$ & & \\
\hline
\end{tabular}

Page 14/27 


\begin{tabular}{|llll|} 
Satisfactory & $277(48.0 \%)$ & $148(41.6 \%)$ & $129(58.4 \%)$ \\
\hline Excellent & $238(41.2 \%)$ & $178(50.0 \%)$ & $60(27.1 \%)$ \\
\hline
\end{tabular}

*It is not appliable to conduct $\chi^{2}$ test as the number in one cell of Chinese data is less than 5 .

Table 2. Descriptive statistics for the associations of demographic information, past behaviors with three preventive behaviors, as well as motivational factors and volitional factors in the total sample $(n=560-578)$ 


\begin{tabular}{|c|c|c|c|c|c|c|}
\hline & \multicolumn{2}{|c|}{ Hand washing } & \multicolumn{2}{|c|}{ Facemask wearing } & \multicolumn{2}{|c|}{ Physical distancing } \\
\hline & Mean (SD) & $F / t / r$ & Mean (SD) & $F / t / r$ & Mean (SD) & $F / t / r$ \\
\hline Total & $3.35(0.6)$ & & $3.76(0.51)$ & & $3.64(0.48)$ & \\
\hline \multicolumn{7}{|l|}{ Country } \\
\hline China & $3.55(0.51)$ & $10.78^{a^{\star \star \star}}$ & $3.73(0.56)$ & -1.63 & $3.62(0.48)$ & -.87 \\
\hline Germany & $3.02(0.6)$ & & $3.80(0.48)$ & & $3.66(0.49)$ & \\
\hline Age & & $-.09^{*}$ & & .01 & & -.03 \\
\hline \multicolumn{7}{|l|}{ Gender } \\
\hline Female & $3.30(0.59)$ & -1.87 & $3.76(0.49)$ & .18 & $3.67(0.47)$ & 1.29 \\
\hline Male & $3.39(0.61)$ & & $3.76(0.53)$ & & $3.61(0.49)$ & \\
\hline \multicolumn{7}{|l|}{ Marital status } \\
\hline Single & $3.13(0.63)$ & $-7.88^{a^{\star \star \star}}$ & $3.76(0.53)$ & .08 & $3.63(0.49)$ & -.44 \\
\hline Married & $3.52(0.52)$ & & $3.76(0.5)$ & & $3.64(0.47)$ & \\
\hline \multicolumn{7}{|l|}{ Education level } \\
\hline Primary school or below & $3.25(0.68)$ & 2.94 & $3.78(0.40)$ & 2.72 & $3.59(0.53)$ & 1.87 \\
\hline Secondary school & $3.43(0.57)$ & & $3.70(0.56)$ & & $3.60(0.50)$ & \\
\hline University or above & $3.31(0.62)$ & & $3.80(0.48)$ & & $3.67(0.44)$ & \\
\hline \multicolumn{7}{|l|}{ Occupation status } \\
\hline Employed & $3.05(0.62)$ & $3.89^{\star \star \star}$ & $3.75(0.52)$ & .09 & $3.60(0.56)$ & .58 \\
\hline Unemployed & $3.38(0.60)$ & & $3.76(0.46)$ & & $3.64(0.47)$ & \\
\hline \multicolumn{7}{|l|}{ Household income } \\
\hline Below the average & $3.34(0.63)$ & $4.27^{\star}$ & $3.66(0.53)$ & 2.87 & $3.57(0.47)$ & 2.04 \\
\hline Average & $3.41(0.56)$ & & $3.75(0.56)$ & & $3.63(0.51)$ & \\
\hline Above the average & $3.25(0.65)$ & & $3.76(0.51)$ & & $3.69(0.44)$ & \\
\hline \multicolumn{7}{|l|}{ Children status } \\
\hline Yes (have children) & $3.39(0.59)$ & $4.66^{* \star *}$ & $3.76(0.50)$ & -.28 & $3.64(0.47)$ & -.73 \\
\hline No & $3.00(0.58)$ & & $3.78(0.57)$ & & $3.68(0.54)$ & \\
\hline \multicolumn{7}{|l|}{ Living situation } \\
\hline Living alone & $3.19(0.67)$ & $-2.73^{a^{\star}}$ & $3.66(0.66)$ & -1.84 & $3.68(0.49)$ & .84 \\
\hline Living with children/spouse & $3.38(0.58)$ & & $3.78(0.47)$ & & $3.63(0.48)$ & \\
\hline \multicolumn{7}{|l|}{ Chronic disease } \\
\hline Yes & $3.38(0.61)$ & 1.32 & $3.75(0.55)$ & -.3 & $3.66(0.48)$ & 1.01 \\
\hline No & $3.31(0.60)$ & & $3.77(0.47)$ & & $3.62(0.49)$ & \\
\hline
\end{tabular}




\begin{tabular}{|c|c|c|c|c|c|c|}
\hline \multicolumn{7}{|l|}{ Infected acquaintances } \\
\hline Yes & $3.17(0.61)$ & $-3.86^{\star \star \star}$ & $3.75(0.60)$ & -.32 & $3.59(0.50)$ & -1.31 \\
\hline No & $3.40(0.59)$ & & $3.77(0.48)$ & & $3.65(0.48)$ & \\
\hline Perceived health status & & 2.33 & & .75 & & 1.50 \\
\hline Bad & $3.26(0.69)$ & & $3.81(0.50)$ & & $3.71(0.42)$ & \\
\hline Satisfactory & $3.32(0.63)$ & & $3.77(0.55)$ & & $3.66(0.49)$ & \\
\hline Excellent & $3.41(0.55)$ & & $3.73(0.47)$ & & $3.60(0.48)$ & \\
\hline BMI & & $-.19^{\star \star \star}$ & & .05 & & -.02 \\
\hline Past behavior & $2.94(0.70)$ & $.49^{\star \star \star}$ & $2.53(1.16)$ & $.09^{*}$ & $2.87(0.90)$ & $.29^{\star \star \star}$ \\
\hline \multicolumn{7}{|l|}{ Motivational factors } \\
\hline Health knowledge & $4.22(0.70)$ & & $3.69(0.99)$ & & $3.65(0.99)$ & \\
\hline Attitude & $5.47(0.94)$ & & $5.50(1.02)$ & & $5.62(0.88)$ & \\
\hline Subjective norm & $5.64(0.85)$ & & $5.66(0.90)$ & & $5.68(0.80)$ & \\
\hline Risk perception & $4.06(1.66)$ & & $4.89(1.32)$ & & $4.85(1.35)$ & \\
\hline Motivational self-efficacy & $5.60(0.92)$ & & $5.76(0.76)$ & & $5.50(0.95)$ & \\
\hline Intention & $5.67(0.76)$ & & $5.67(0.95)$ & & $5.68(0.79)$ & \\
\hline \multicolumn{7}{|l|}{ Volitional factors } \\
\hline Volitional self-efficacy & $5.59(0.95)$ & & $5.73(0.85)$ & & $5.63(0.84)$ & \\
\hline Planning & $5.35(1.16)$ & & $5.59(0.96)$ & & $5.47(0.97)$ & \\
\hline Self-monitoring & $5.31(1.22)$ & & $5.66(0.89)$ & & $5.44(1.07)$ & \\
\hline
\end{tabular}

Note. ${ }^{a}$ adjuste

Table 3. Results of univariate regressions between motivational factors, volitional factors and preventive behaviors $(n=560-$ 578) 


\begin{tabular}{|c|c|c|c|c|c|c|c|c|c|}
\hline & \multicolumn{3}{|c|}{ Hand washing } & \multicolumn{3}{|c|}{ Facemask wearing } & \multicolumn{3}{|c|}{ Physical distancing } \\
\hline & $\mathrm{B}(95 \% \mathrm{Cl})$ & $\beta$ & $f^{2}$ & $\mathrm{~B}(95 \% \mathrm{Cl})$ & $\beta$ & $f^{2}$ & $\mathrm{~B}(95 \% \mathrm{Cl})$ & $\beta$ & $f^{2}$ \\
\hline \multicolumn{10}{|l|}{ Motivational factors } \\
\hline \multirow[t]{2}{*}{ Health knowledge } & .16 & $.18^{* * \star}$ & $.03^{* \star \star}$ & -.002 & -.003 & .003 & .06 & $.11^{*}$ & $.01^{*}$ \\
\hline & {$[.10, .22]$} & & & {$[-.05, .05]$} & & & {$[.01, .10]$} & & \\
\hline \multirow[t]{2}{*}{ Attitude } & .15 & $.23^{\star \star \star}$ & $.04^{\star \star \star}$ & & $.25^{\star \star \star}$ & $.06^{\star \star \star}$ & & $.27^{\star \star \star}$ & $.07^{\star \star \star}$ \\
\hline & {$[.10, .19]$} & & & {$[.08, .17]$} & & & {$[.10, .19]$} & & \\
\hline \multirow[t]{2}{*}{ Subjective norm } & .14 & $.19^{\star \star \star}$ & $.03^{\star \star \star}$ & .16 & $.28^{\star \star \star}$ & $.08^{\star \star \star}$ & .14 & $.23^{\star \star \star}$ & $.05^{\star \star \star}$ \\
\hline & {$[.09, .19]$} & & & {$[.11, .21]$} & & & {$[.09, .19]$} & & \\
\hline \multirow[t]{2}{*}{ Risk perception } & .02 & .05 & .002 & .05 & $.12^{\star \star}$ & $.01^{\star \star}$ & .03 & $.09^{*}$ & $.01^{*}$ \\
\hline & {$[-.01, .05]$} & & & {$[.01, .08]$} & & & {$[.004, .06]$} & & \\
\hline \multirow[t]{2}{*}{ Motivational self-efficacy } & .11 & $.17^{\star \star \star}$ & $.02^{\star \star \star}$ & & $.35^{\star \star \star}$ & $.14^{\star \star \star}$ & & $.29^{\star \star \star}$ & $.08^{\star \star \star}$ \\
\hline & {$[.06, .15]$} & & & {$[.19, .29]$} & & & {$[.11, .19]$} & & \\
\hline \multirow[t]{2}{*}{ Intention } & .21 & $.27^{\star \star \star}$ & $.06^{\star \star \star}$ & .14 & $.25^{\star \star \star}$ & $.06^{\star \star \star}$ & .22 & $.37^{\star \star \star}$ & $.13^{\star \star \star}$ \\
\hline & {$[.16, .27]$} & & & {$[.09, .18]$} & & & {$[.18, .27]$} & & \\
\hline \multicolumn{10}{|l|}{ Volitional factors } \\
\hline \multirow[t]{2}{*}{ Volitional self-efficacy } & .14 & $.23^{\star \star \star}$ & $.05^{\star \star \star}$ & .21 & $.36^{\star \star \star}$ & $.14^{\star \star \star}$ & .23 & $.40^{\star \star \star}$ & $.17^{\star \star \star}$ \\
\hline & {$[.10, .19]$} & & & {$[.16, .26]$} & & & {$[.19, .28]$} & & \\
\hline \multirow[t]{2}{*}{ Planning } & .17 & $.32^{\star \star \star}$ & $.08^{\star \star \star}$ & .18 & $.34^{\star \star \star}$ & $.11^{\star \star \star}$ & .16 & $.33^{\star \star \star}$ & $.10^{\star \star \star}$ \\
\hline & {$[.13, .21]$} & & & {$[.14, .22]$} & & & {$[.12, .20]$} & & \\
\hline \multirow[t]{2}{*}{ Self-monitoring } & .13 & $.26^{\star \star \star}$ & $.05^{\star \star \star}$ & .21 & $.36^{\star \star \star}$ & $.14^{\star \star \star}$ & .12 & $.27^{\star \star \star}$ & $.06^{\star \star \star}$ \\
\hline & {$[.09, .16]$} & & & {$[.16, .25]$} & & & {$[.08, .16]$} & & \\
\hline
\end{tabular}

Table 4. Multiple hierarchical regression results for prediction of hand washing behavior $(n=560)$ 


\begin{tabular}{|c|c|c|c|c|c|c|c|c|c|c|}
\hline \multirow[t]{2}{*}{ Variables } & \multicolumn{2}{|l|}{ Model 1} & \multicolumn{2}{|l|}{ Model 2} & \multicolumn{2}{|l|}{ Model 3} & \multicolumn{2}{|l|}{ Model 4} & \multicolumn{2}{|l|}{ Model 5} \\
\hline & $\mathrm{B}[95 \% \mathrm{Cl}]$ & $\beta$ & $\begin{array}{l}\mathrm{B} \\
{[95 \% \mathrm{Cl}]}\end{array}$ & $\beta$ & $\mathrm{B}[95 \% \mathrm{Cl}]$ & $\beta$ & $\mathrm{B}[95 \% \mathrm{Cl}]$ & $\beta$ & $\mathrm{B}[95 \% \mathrm{Cl}]$ & $\beta$ \\
\hline \multirow[t]{2}{*}{ Age } & -.002 & -.02 & -.001 & -.01 & $<.001$ & -.003 & $<.001$ & -.002 & .001 & .01 \\
\hline & $\begin{array}{l}{[-.01} \\
.01]\end{array}$ & & $\begin{array}{l}{[-.01} \\
.01]\end{array}$ & & $\begin{array}{l}{[-.01} \\
.01]\end{array}$ & & {$[-.01 . .01]$} & & $\begin{array}{l}{[-.01} \\
.01]\end{array}$ & \\
\hline \multirow[t]{2}{*}{ Marital status } & .23 & $.19^{\star \star \star}$ & .20 & $.16^{\star \star \star}$ & .18 & $.15^{\star \star \star}$ & .08 & .06 & .07 & .05 \\
\hline & {$[.13, .33]$} & & {$[.11, .29]$} & & {$[.09, .27]$} & & {$[-.03, .18]$} & & $\begin{array}{l}{[-.04,} \\
.17]\end{array}$ & \\
\hline \multirow[t]{2}{*}{ Occupation } & -.15 & -.07 & -.11 & -.05 & -.10 & -.05 & -.03 & -.02 & -.02 & -.01 \\
\hline & $\begin{array}{l}{[-.31} \\
.01]\end{array}$ & & $\begin{array}{l}{[-.26} \\
.04]\end{array}$ & & $\begin{array}{l}{[-25,} \\
.05]\end{array}$ & & {$[-.18, .12]$} & & $\begin{array}{l}{[-.17} \\
.13]\end{array}$ & \\
\hline \multirow{2}{*}{$\begin{array}{l}\text { Household } \\
\text { income }\end{array}$} & .01 & .01 & -.01 & -.01 & -.01 & -.01 & .02 & .02 & .02 & .02 \\
\hline & $\begin{array}{l}{[-.06,} \\
.07]\end{array}$ & & $\begin{array}{l}{[-.07} \\
.05]\end{array}$ & & $\begin{array}{l}{[-.07,} \\
.06]\end{array}$ & & {$[-.04, .08]$} & & $\begin{array}{l}{[-.04,} \\
.08]\end{array}$ & \\
\hline \multirow{2}{*}{$\begin{array}{l}\text { Children } \\
\text { status }\end{array}$} & -.14 & -.07 & -.12 & -.06 & -.10 & -.05 & -.04 & -.02 & -.05 & -.02 \\
\hline & $\begin{array}{l}{[-.30} \\
.01]\end{array}$ & & $\begin{array}{l}{[-.26} \\
.03]\end{array}$ & & $\begin{array}{l}{[-24,} \\
.04]\end{array}$ & & {$[-.19, .10]$} & & $\begin{array}{l}{[-19,} \\
.10]\end{array}$ & \\
\hline \multirow{2}{*}{$\begin{array}{l}\text { Living } \\
\text { situation }\end{array}$} & .06 & .04 & .03 & .02 & .01 & .01 & -.03 & -.02 & -.03 & -.02 \\
\hline & $\begin{array}{l}{[-.06,} \\
.17]\end{array}$ & & $\begin{array}{l}{[-.07,} \\
.14]\end{array}$ & & $\begin{array}{l}{[-.10,} \\
.12]\end{array}$ & & {$[-.14, .08]$} & & $\begin{array}{l}{[-.14,} \\
.08]\end{array}$ & \\
\hline \multirow{2}{*}{$\begin{array}{l}\text { Infected } \\
\text { acquaintances }\end{array}$} & -.001 & -.001 & .003 & .002 & .003 & .002 & .001 & $<$ & -.002 & -.002 \\
\hline & $\begin{array}{l}{[-.11} \\
.11]\end{array}$ & & {$[-10, .11]$} & & {$[-.10,10]$} & & {$[-.10, .10]$} & & $\begin{array}{l}{[-10,} \\
.10]\end{array}$ & \\
\hline \multirow[t]{2}{*}{ BMI } & -.02 & $-.10^{* *}$ & -.01 & $-.08^{*}$ & -.01 & $-.08^{*}$ & -.01 & -.06 & -.01 & -.05 \\
\hline & $\begin{array}{l}{[-.03} \\
-.004]\end{array}$ & & $\begin{array}{l}{[-.02,} \\
-.003]\end{array}$ & & $\begin{array}{l}{[-.02,} \\
-.002]\end{array}$ & & {$[-.02, .001]$} & & $\begin{array}{l}{[-.02,} \\
.002]\end{array}$ & \\
\hline \multirow[t]{2}{*}{ Past behavior } & .37 & $.43^{* \star *}$ & .23 & $.27^{\star \star \star}$ & .22 & $.25^{\star \star \star}$ & .21 & $.24^{\star \star \star}$ & .19 & $.22^{\star \star *}$ \\
\hline & {$[.31, .43]$} & & {$[.17, .29]$} & & {$[.15, .28]$} & & {$[.14, .27]$} & & {$[.13, .26]$} & \\
\hline \multirow{2}{*}{$\begin{array}{l}\text { Health } \\
\text { knowledge }\end{array}$} & & & .08 & $.13^{* \star *}$ & .08 & $.13^{* \star *}$ & .10 & $.17^{\star \star \star}$ & .10 & $.17^{* k *}$ \\
\hline & & & {$[.04, .12]$} & & {$[.04, .12]$} & & {$[.06, .14]$} & & {$[.06, .15]$} & \\
\hline \multirow{2}{*}{$\begin{array}{l}\text { Subjective } \\
\text { norm }\end{array}$} & & & .05 & .08 & .03 & .05 & .02 & .03 & -.01 & -.02 \\
\hline & & & $\begin{array}{l}{[-.01} \\
.10]\end{array}$ & & $\begin{array}{l}{[-.02,} \\
.09]\end{array}$ & & {$[-.03, .07]$} & & $\begin{array}{l}{[-.08,} \\
.06]\end{array}$ & \\
\hline \multirow[t]{2}{*}{ Attitude } & & & .08 & $.13^{\star \star}$ & .05 & .08 & .04 & .07 & .06 & $.10^{*}$ \\
\hline & & & {$[.03, .13]$} & & $\begin{array}{l}{[-.002,} \\
.10]\end{array}$ & & {$[-.01, .09]$} & & {$[.01, .11]$} & \\
\hline \multirow{2}{*}{$\begin{array}{l}\text { Motivational } \\
\text { self-efficacy }\end{array}$} & & & -.001 & -.001 & -.03 & -.05 & -.03 & -.04 & -.02 & -.04 \\
\hline & & & $\begin{array}{l}{[-.05} \\
.05]\end{array}$ & & $\begin{array}{l}{[-.08,} \\
.02]\end{array}$ & & {$[-.08, .03]$} & & $\begin{array}{l}{[-.08,} \\
.03]\end{array}$ & \\
\hline Intention & & & .12 & $.20^{\star \star \star}$ & .06 & $.10^{*}$ & .06 & $.10^{*}$ & .03 & .06 \\
\hline
\end{tabular}




\begin{tabular}{|c|c|c|c|c|c|c|}
\hline & $\begin{array}{l}{[.001} \\
.12]\end{array}$ & & {$[.004, .12]$} & & $\begin{array}{l}{[-.03} \\
.10]\end{array}$ & \\
\hline \multirow{2}{*}{$\begin{array}{l}\text { Volitional self- } \\
\text { efficacy }\end{array}$} & .04 & .06 & .04 & .06 & .08 & $.13^{*}$ \\
\hline & $\begin{array}{l}{[-.02} \\
.09]\end{array}$ & & {$[-.02, .09]$} & & {$[.02, .14]$} & \\
\hline \multirow[t]{2}{*}{ Planning } & .11 & $.18^{\star \star}$ & .10 & $.16^{\star \star}$ & .13 & $.21^{\star \star}$ \\
\hline & {$[.04, .18]$} & & {$[.03, .16]$} & & {$[.03, .22]$} & \\
\hline \multirow{2}{*}{$\begin{array}{l}\text { Self- } \\
\text { monitoring }\end{array}$} & .02 & .04 & .02 & .03 & .02 & .03 \\
\hline & $\begin{array}{l}{[-.04} \\
.09]\end{array}$ & & {$[-.05, .08]$} & & $\begin{array}{l}{[-.05} \\
.09]\end{array}$ & \\
\hline \multirow[t]{2}{*}{ Country } & & & -.12 & $-.20^{\star \star \star}$ & -.13 & $-.22^{\star \star \star}$ \\
\hline & & & {$[-.19,-.06]$} & & $\begin{array}{l}{[-.20} \\
-.06]\end{array}$ & \\
\hline \multirow{2}{*}{$\begin{array}{l}\text { Country } x \\
\text { Health } \\
\text { knowledge }\end{array}$} & & & & & .01 & .02 \\
\hline & & & & & $\begin{array}{l}{[-.03} \\
.06]\end{array}$ & \\
\hline \multirow{2}{*}{$\begin{array}{l}\text { Country } x \\
\text { Subjective } \\
\text { norm }\end{array}$} & & & & & .05 & .10 \\
\hline & & & & & $\begin{array}{l}{[-.01} \\
.11]\end{array}$ & \\
\hline \multirow{2}{*}{$\begin{array}{l}\text { Country } x \\
\text { Attitude }\end{array}$} & & & & & -.02 & -.04 \\
\hline & & & & & $\begin{array}{l}{[-.07} \\
.03]\end{array}$ & \\
\hline \multirow{2}{*}{$\begin{array}{l}\text { Country } x \\
\text { Motivational } \\
\text { self-efficacy }\end{array}$} & & & & & .01 & .01 \\
\hline & & & & & $\begin{array}{l}{[-.04} \\
.06]\end{array}$ & \\
\hline \multirow{2}{*}{$\begin{array}{l}\text { Country } \times \\
\text { Intention }\end{array}$} & & & & & .05 & .08 \\
\hline & & & & & $\begin{array}{l}{[-.01} \\
.10]\end{array}$ & \\
\hline \multirow{2}{*}{$\begin{array}{l}\text { Country } \times \\
\text { Volitional self- } \\
\text { efficacy }\end{array}$} & & & & & -.08 & $-.15^{\star \star}$ \\
\hline & & & & & $\begin{array}{l}{[-.13} \\
-.02]\end{array}$ & \\
\hline \multirow{2}{*}{$\begin{array}{l}\text { Country } \times \\
\text { Planning }\end{array}$} & & & & & -.03 & -.06 \\
\hline & & & & & $\begin{array}{l}{[-.11} \\
.05]\end{array}$ & \\
\hline \multirow{2}{*}{$\begin{array}{l}\text { Country } \times \text { Self- } \\
\text { monitoring }\end{array}$} & & & & & -.02 & -.03 \\
\hline & & & & & $\begin{array}{l}{[-.08} \\
.05]\end{array}$ & \\
\hline
\end{tabular}

Note. The coding was

Marital status $0=$ single; $1=$ partnered

Occupation $0=$ unemployed, $1=($ self-)employed/working 
Household income 0 = below average; 1 = average; 2 =above average

Children status $0=$ no children, $1=$ one or more child

Living situation 0 living alone, 1=living with children/spouse

Infected acquaintances $0=$ no infected acquaintances; $1=$ infected acquaintances

Table 5 Multiple hierarchical regression results for prediction of facemask wearing behavior $(n=578)$ 


\begin{tabular}{|c|c|c|c|c|c|c|c|c|c|c|}
\hline \multirow[t]{2}{*}{ Variables } & \multicolumn{2}{|l|}{ Model 1} & \multicolumn{2}{|l|}{ Model 2} & \multicolumn{2}{|l|}{ Model 3} & \multicolumn{2}{|l|}{ Model 4} & \multicolumn{2}{|l|}{ Model 5} \\
\hline & $\mathrm{B}[95 \% \mathrm{Cl}]$ & $\beta$ & $\mathrm{B}[95 \% \mathrm{Cl}]$ & $\beta$ & $\mathrm{B}[95 \% \mathrm{Cl}]$ & $\beta$ & $\mathrm{B}[95 \% \mathrm{Cl}]$ & $\beta$ & $\mathrm{B}[95 \% \mathrm{Cl}]$ & $\beta$ \\
\hline \multirow[t]{2}{*}{ Past behavior } & .04 & $.09^{*}$ & .003 & .04 & .003 & .01 & .09 & $.20^{\star * \star}$ & .08 & $.19^{\star \star \star}$ \\
\hline & {$[.01, .08]$} & & $\begin{array}{l}{[-.03,} \\
.04]\end{array}$ & & {$[-.03, .04]$} & & {$[.05, .14]$} & & {$[.04, .13]$} & \\
\hline \multirow[t]{2}{*}{ Risk perception } & & & -.01 & -.03 & -.02 & -.03 & -.01 & -.01 & -.01 & -.01 \\
\hline & & & $\begin{array}{l}{[-06,} \\
.03]\end{array}$ & & {$[-.06, .03]$} & & $\begin{array}{l}{[-05,} \\
.04]\end{array}$ & & $\begin{array}{l}{[-.06,} \\
.06]\end{array}$ & \\
\hline \multirow[t]{2}{*}{ Subjective norm } & & & .02 & .04 & -.003 & -.01 & .02 & .05 & -.01 & -.02 \\
\hline & & & $\begin{array}{l}{[-.04,} \\
.08]\end{array}$ & & {$[-.07, .06]$} & & $\begin{array}{l}{[-.04,} \\
.09]\end{array}$ & & $\begin{array}{l}{[-.09,} \\
.07]\end{array}$ & \\
\hline \multirow[t]{2}{*}{ Attitude } & & & .01 & .02 & -.01 & -.02 & .01 & .01 & .004 & .01 \\
\hline & & & {$[-.05$,} & & {$[-.07, .05]$} & & $\begin{array}{l}{[-.05,} \\
.06]\end{array}$ & & $\begin{array}{l}{[-.06,} \\
.06]\end{array}$ & \\
\hline \multirow{2}{*}{$\begin{array}{l}\text { Motivational self- } \\
\text { efficacy }\end{array}$} & & & .15 & $.30^{* * *}$ & .10 & $.19^{* *}$ & .08 & $.16^{*}$ & .11 & $.21^{*}$ \\
\hline & & & {$[.08, .22]$} & & {$[.02, .17]$} & & {$[.01, .15]$} & & {$[.02, .19]$} & \\
\hline \multirow[t]{2}{*}{ Intention } & & & .02 & .04 & -.03 & -.06 & -.01 & -.02 & -.02 & -.04 \\
\hline & & & $\begin{array}{l}{[-.03,} \\
.07]\end{array}$ & & {$[-.08, .03]$} & & $\begin{array}{l}{[-.06,} \\
.05]\end{array}$ & & $\begin{array}{l}{[-10} \\
.05]\end{array}$ & \\
\hline \multirow{2}{*}{$\begin{array}{l}\text { Volitional self- } \\
\text { efficacy }\end{array}$} & & & & & .07 & $.14^{*}$ & .05 & .10 & .03 & .06 \\
\hline & & & & & {$[.01, .13]$} & & $\begin{array}{l}{[-.01} \\
.11]\end{array}$ & & $\begin{array}{l}{[-.03,} \\
.09]\end{array}$ & \\
\hline \multirow[t]{2}{*}{ Planning } & & & & & .04 & .08 & .04 & .07 & .06 & .11 \\
\hline & & & & & {$[-.03, .11]$} & & {$[-.04$,} & & $\begin{array}{l}{[-.05,} \\
.16]\end{array}$ & \\
\hline \multirow[t]{2}{*}{ Self-monitoring } & & & & & .07 & .14 & .07 & .14 & .13 & $.25^{* \star}$ \\
\hline & & & & & {$[-.004, .15]$} & & $\begin{array}{l}{[-.003,} \\
.14]\end{array}$ & & {$[.04, .21]$} & \\
\hline \multirow[t]{2}{*}{ Country } & & & & & & & .16 & $.32^{\star \star \star}$ & .16 & $.31^{\star \star \star}$ \\
\hline & & & & & & & {$[.11, .22]$} & & {$[.10,21]$} & \\
\hline \multirow{2}{*}{$\begin{array}{l}\text { Country } \times \text { Risk } \\
\text { perception }\end{array}$} & & & & & & & & & .003 & .01 \\
\hline & & & & & & & & & $\begin{array}{l}{[-.04} \\
.05]\end{array}$ & \\
\hline \multirow{2}{*}{$\begin{array}{l}\text { Country } x \\
\text { Subjective norm }\end{array}$} & & & & & & & & & .05 & .11 \\
\hline & & & & & & & & & $\begin{array}{l}{[-.02,} \\
.12]\end{array}$ & \\
\hline \multirow{2}{*}{$\begin{array}{l}\text { Country } x \\
\text { Attitude }\end{array}$} & & & & & & & & & .02 & .03 \\
\hline & & & & & & & & & $\begin{array}{l}{[-.04,} \\
.07]\end{array}$ & \\
\hline $\begin{array}{l}\text { Country } \times \\
\text { Motivational self- } \\
\text { efficacy }\end{array}$ & & & & & & & & & -.03 & -.06 \\
\hline
\end{tabular}




\begin{tabular}{|c|c|c|}
\hline & $\begin{array}{l}{[-.10} \\
.05]\end{array}$ & \\
\hline \multirow{2}{*}{$\begin{array}{l}\text { Country } \times \\
\text { Intention }\end{array}$} & $<.001$ & \multirow[t]{2}{*}{-.001} \\
\hline & $\begin{array}{l}{[-.06} \\
.06]\end{array}$ & \\
\hline \multirow{2}{*}{$\begin{array}{l}\text { Country } \times \\
\text { Volitional self- } \\
\text { efficacy }\end{array}$} & .05 & \multirow[t]{2}{*}{.12} \\
\hline & $\begin{array}{l}{[-.01} \\
.11]\end{array}$ & \\
\hline \multirow{2}{*}{$\begin{array}{l}\text { Country } \times \\
\text { Planning }\end{array}$} & -.01 & \multirow[t]{2}{*}{-.02} \\
\hline & {$[.09, .08$} & \\
\hline \multirow{2}{*}{$\begin{array}{l}\text { Country } \times \text { Self- } \\
\text { monitoring }\end{array}$} & -.12 & \multirow[t]{2}{*}{$-.28^{\star \star}$} \\
\hline & $\begin{array}{l}{[-.20,} \\
-.05]\end{array}$ & \\
\hline
\end{tabular}

Table 6 Multiple hierarchical regression results for prediction of physical distancing behavior $(n=578)$ 


\begin{tabular}{|c|c|c|c|c|c|c|c|c|c|c|}
\hline \multirow[t]{2}{*}{ Variables } & \multicolumn{2}{|l|}{ Model 1} & \multicolumn{2}{|l|}{ Model 2} & \multicolumn{2}{|l|}{ Model 3} & \multicolumn{2}{|l|}{ Model 4} & \multicolumn{2}{|l|}{ Model 5} \\
\hline & $\mathrm{B}[95 \% \mathrm{Cl}]$ & $\beta$ & $\mathrm{B}[95 \% \mathrm{Cl}]$ & $\beta$ & $\mathrm{B}[95 \% \mathrm{Cl}]$ & $\beta$ & $\mathrm{B}[95 \% \mathrm{Cl}]$ & $\beta$ & $\mathrm{B}[95 \% \mathrm{Cl}]$ & $\beta$ \\
\hline \multirow[t]{2}{*}{ Past behavior } & .16 & $.29^{* \star \star \star}$ & .06 & $.11^{*}$ & .06 & $.12^{\star \star}$ & .10 & $.19^{\star \star \star}$ & .09 & $.17^{\star \star \star}$ \\
\hline & {$[.11, .20]$} & & {$[.01, .11]$} & & {$[.02, .11]$} & & {$[.06, .14]$} & & {$[.05, .13]$} & \\
\hline \multirow{2}{*}{$\begin{array}{l}\text { Health } \\
\text { knowledge }\end{array}$} & & & .02 & .04 & .02 & .05 & .07 & $.14^{\star \star \star}$ & .08 & $.16^{\star \star \star *}$ \\
\hline & & & $\begin{array}{l}{[-.02} \\
.06]\end{array}$ & & $\begin{array}{l}{[-.02} \\
.06]\end{array}$ & & {$[.03, .11]$} & & {$[.04, .12]$} & \\
\hline \multirow[t]{2}{*}{ Risk perception } & & & -.01 & -.01 & -.01 & -.02 & .02 & .04 & .02 & .03 \\
\hline & & & $\begin{array}{l}{[-.05} \\
.03]\end{array}$ & & $\begin{array}{l}{[-.05,} \\
.03]\end{array}$ & & $\begin{array}{l}{[-02,} \\
.06]\end{array}$ & & $\begin{array}{l}{[-.02,} \\
.05]\end{array}$ & \\
\hline \multirow[t]{2}{*}{ Subjective norm } & & & .02 & .05 & .01 & .03 & .02 & .04 & .01 & .01 \\
\hline & & & $\begin{array}{l}{[-.02,} \\
.07]\end{array}$ & & $\begin{array}{l}{[-.03,} \\
.06]\end{array}$ & & {$\left[\begin{array}{l}{[-02,} \\
.07]\end{array}\right.$} & & $\begin{array}{l}{[-.04,} \\
.06]\end{array}$ & \\
\hline \multirow[t]{2}{*}{ Attitude } & & & .04 & .08 & .02 & .04 & .01 & .01 & -.01 & -.02 \\
\hline & & & $\begin{array}{l}{[-.01} \\
.09]\end{array}$ & & $\begin{array}{l}{[-.03,} \\
.07]\end{array}$ & & $\begin{array}{l}{[-.04} \\
.05]\end{array}$ & & $\begin{array}{l}{[-.06} \\
.04]\end{array}$ & \\
\hline \multirow{2}{*}{$\begin{array}{l}\text { Motivational } \\
\text { self-efficacy }\end{array}$} & & & .02 & .05 & -.03 & -.05 & .02 & .05 & .05 & .11 \\
\hline & & & $\begin{array}{l}{[-.03,} \\
.08]\end{array}$ & & $\begin{array}{l}{[-09,} \\
.03]\end{array}$ & & $\begin{array}{l}{[-03,} \\
.08]\end{array}$ & & $\begin{array}{l}{[-01,} \\
.12]\end{array}$ & \\
\hline \multirow[t]{2}{*}{ Intention } & & & .13 & $.28^{\star \star \star}$ & .07 & $.14^{*}$ & .05 & .10 & .08 & $.17^{* \star}$ \\
\hline & & & {$[.08, .18]$} & & {$[.02, .13]$} & & {$[-.01, .1]$} & & {$[.01, .16]$} & \\
\hline \multirow{2}{*}{$\begin{array}{l}\text { Volitional self- } \\
\text { efficacy }\end{array}$} & & & & & .13 & $.26^{\star \star \star}$ & .1 & $.19^{\star \star \star}$ & .06 & .13 \\
\hline & & & & & {$[.07, .18]$} & & {$[.04, .15]$} & & $\begin{array}{l}{[-.001,} \\
.12]\end{array}$ & \\
\hline \multirow[t]{2}{*}{ Planning } & & & & & .05 & .10 & .06 & .12 & .12 & $.24^{\star \star}$ \\
\hline & & & & & $\begin{array}{l}{[-01,} \\
.11]\end{array}$ & & $\begin{array}{l}{[-.001} \\
.12]\end{array}$ & & {$[.04, .19]$} & \\
\hline \multirow[t]{2}{*}{ Self-monitoring } & & & & & -.02 & -.04 & .01 & .03 & -.02 & -.04 \\
\hline & & & & & $\begin{array}{l}{[-.08,} \\
.04]\end{array}$ & & $\begin{array}{l}{[-.04,} \\
.07]\end{array}$ & & $\begin{array}{l}{[-.11,} \\
.08]\end{array}$ & \\
\hline \multirow[t]{2}{*}{ Country } & & & & & & & .17 & $.36^{\star \star *}$ & .17 & $.36^{\star * \star}$ \\
\hline & & & & & & & {$[.13, .22]$} & & {$[.13, .22]$} & \\
\hline \multirow{2}{*}{$\begin{array}{l}\text { Country } x \\
\text { Health } \\
\text { knowledge }\end{array}$} & & & & & & & & & -.03 & -.07 \\
\hline & & & & & & & & & $\begin{array}{l}{[-.07} \\
.004]\end{array}$ & \\
\hline \multirow{2}{*}{$\begin{array}{l}\text { Country } \times \text { Risk } \\
\text { perception }\end{array}$} & & & & & & & & & .004 & .01 \\
\hline & & & & & & & & & $\begin{array}{l}{[-.03} \\
.04]\end{array}$ & \\
\hline \multirow{2}{*}{$\begin{array}{l}\text { Country } \times \\
\text { Subjective norm }\end{array}$} & & & & & & & & & .02 & .04 \\
\hline & & & & & & & & & $\begin{array}{l}{[-.03} \\
.06]\end{array}$ & \\
\hline
\end{tabular}




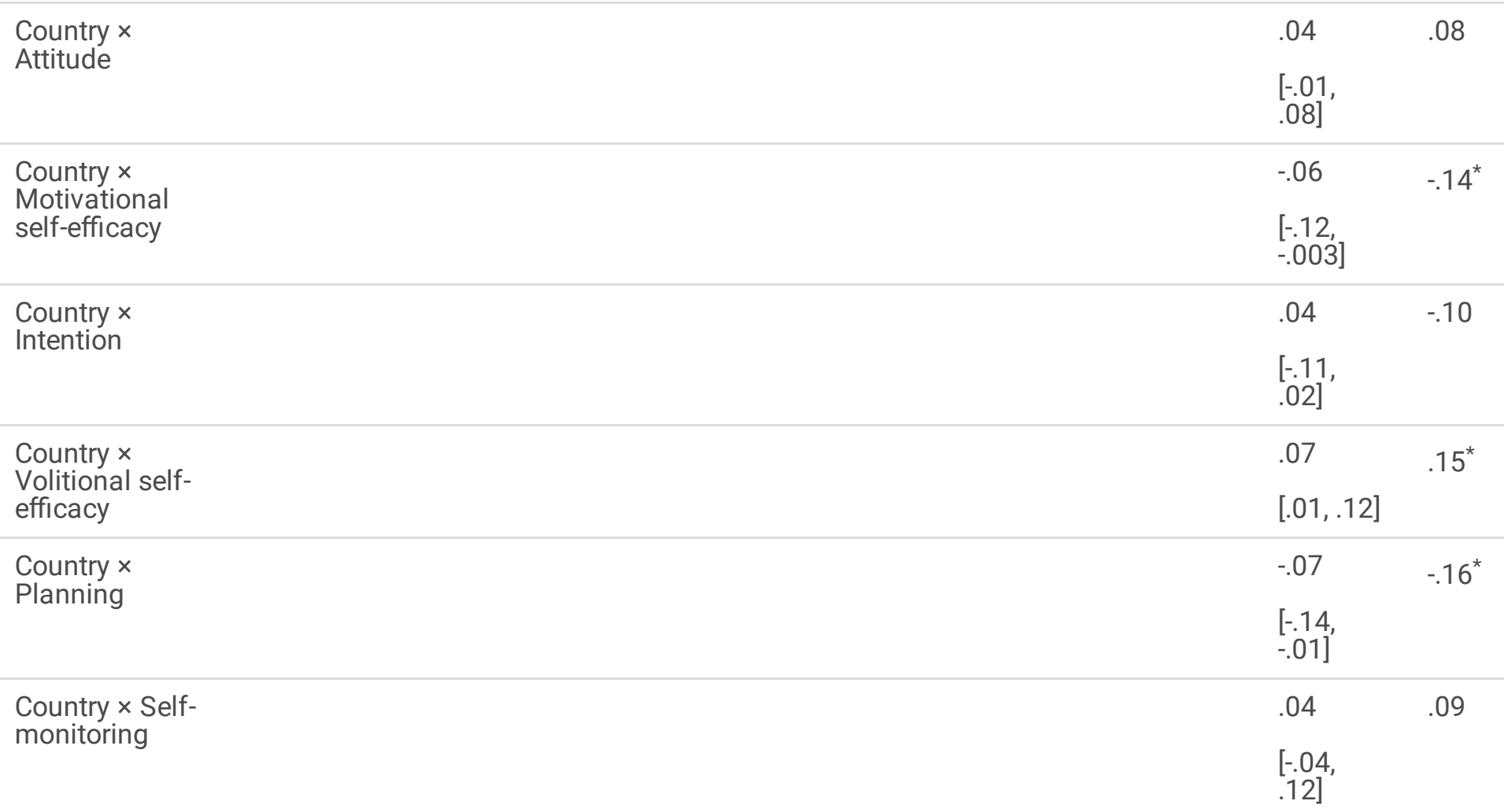

\section{Figures}

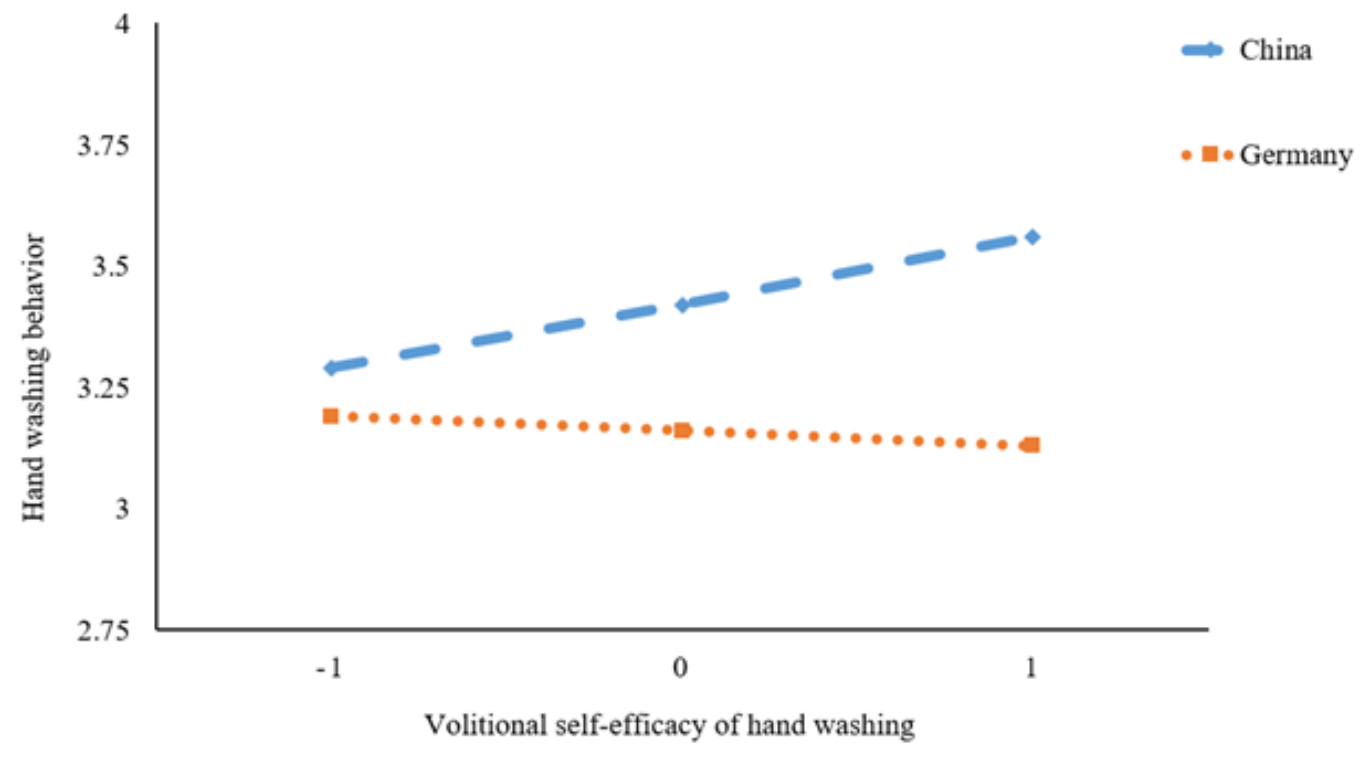

Figure 1

Plot of simple slopes showing the association between volitional self-efficacy and hand washing at different countries $(\mathrm{n}=$ 560) 


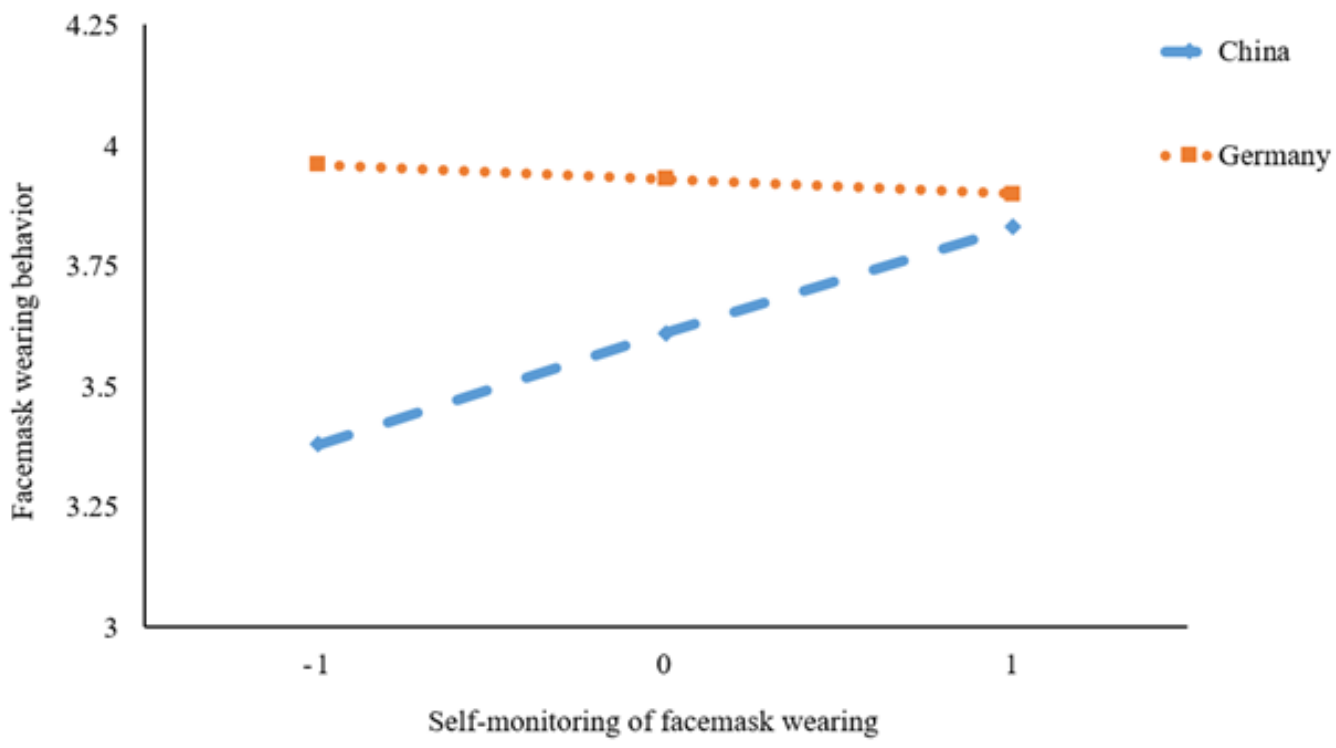

\section{Figure 2}

Plot of simple slopes showing the association between self-monitoring and facemask wearing at different countries $(n=$ 578)

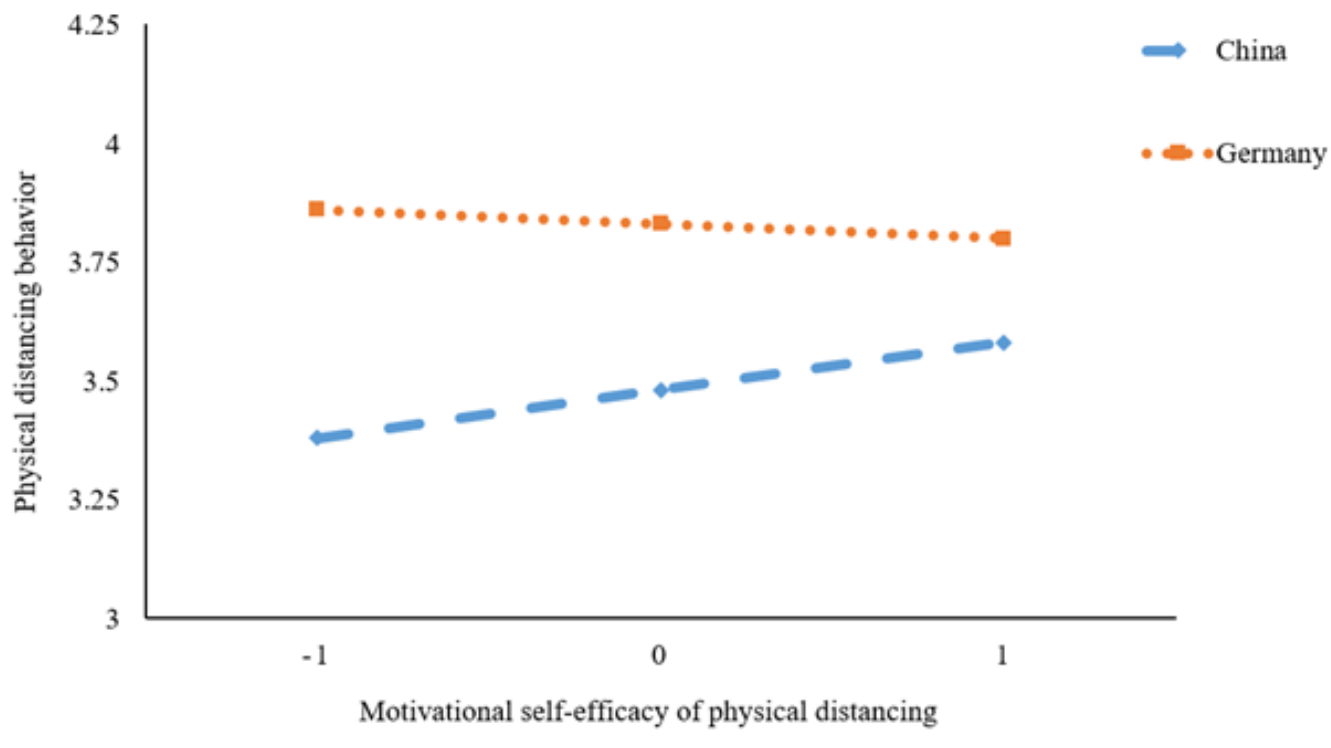

\section{Figure 3}

Plot of simple slopes showing the association between motivational self-efficacy and physical distancing at different countries $(n=578)$ 


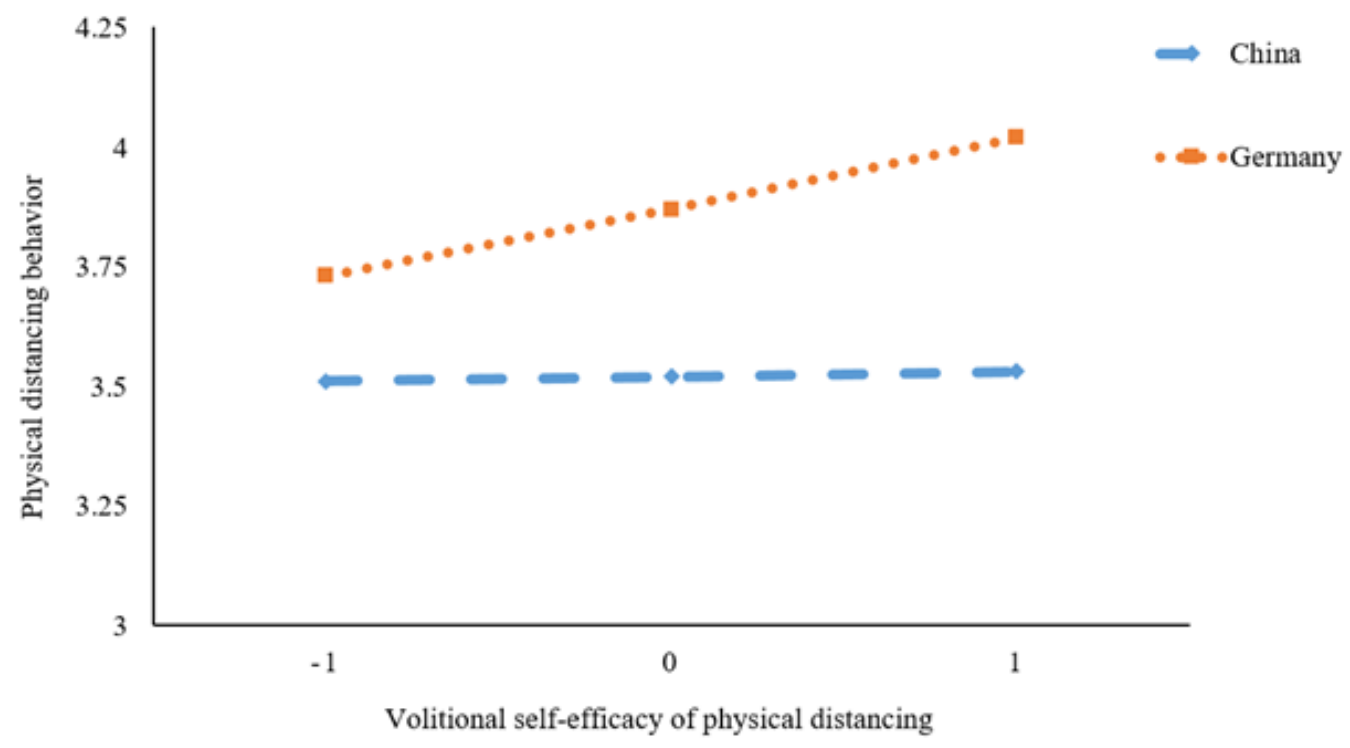

\section{Figure 4}

Plot of simple slopes showing the association between volitional self-efficacy and physical distancing at different countries ( $\mathrm{n}=578$ )

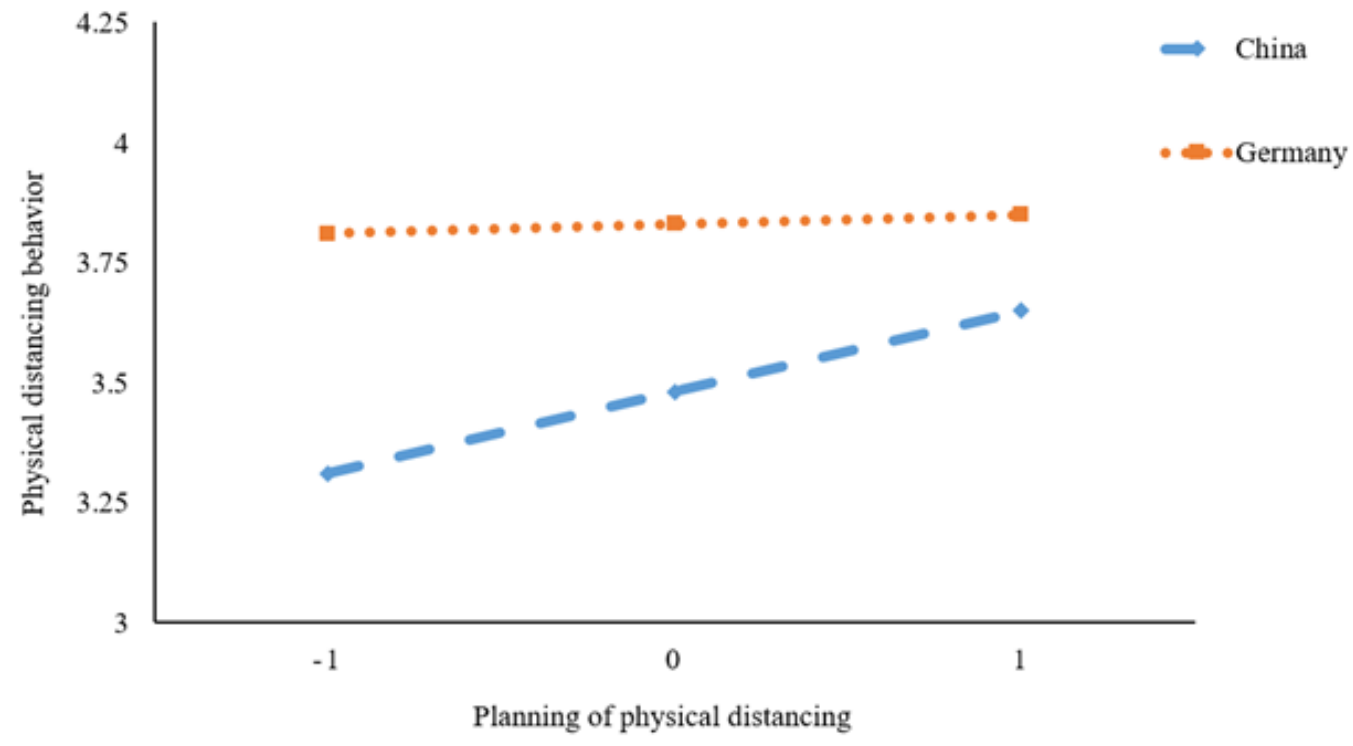

\section{Figure 5}

Plot of simple slopes showing the association between planning and social distancing at different countries $(n=578)$ 